\title{
Effect of Sodium Sulfate, Ammonium Chloride, Ammonium Nitrate, and Salt Mixtures on Aqueous Phase Partitioning of Organic Compounds
}

\author{
Chen Wang, Ying Duan Lei, Frank Wania
}

\begin{abstract}
Version Post-print/accepted manuscript
Citation Wang, C.; Lei, Y. D.; Wania, F. Environ. Sci. Technol. 2016, 50 (23), (published version) 12742-12749.

Publisher's statement This document is the Accepted Manuscript version of a Published Work that appeared in final form in Environmental Science \& Technology, copyright (C) American Chemical Society after peer review and technical editing by the publisher. To access the final edited and published work see DOI: $10.1021 /$ acs.est.6b03525.
\end{abstract}

How to cite TSpace items

Always cite the published version, so the author(s) will receive recognition through services that track citation counts, e.g. Scopus. If you need to cite the page number of the author manuscript from TSpace because you cannot access the published version, then cite the TSpace version in addition to the published version using the permanent URI (handle) found on the record page.

This article was made openly accessible by $U$ of $T$ Faculty.

Please tell us how this access benefits you. Your story matters. 
This document is confidential and is proprietary to the American Chemical Society and its authors. Do not copy or disclose without written permission. If you have received this item in error, notify the sender and delete all copies.

\section{The Effect of Sodium Sulfate, Ammonium Chloride, Ammonium Nitrate and Salt Mixtures on Aqueous Phase Partitioning of Organic Compounds}

\begin{tabular}{|r|l|}
\hline Journal: & Environmental Science \& Technology \\
\hline Manuscript ID & es-2016-03525j.R2 \\
\hline Manuscript Type: & Article \\
\hline Date Submitted by the Author: & 18 -Oct-2016 \\
\hline Complete List of Authors: & $\begin{array}{l}\text { Wang, Chen; University of Toronto, Department of Chemistry } \\
\text { Lei, Ying; University of Toronto Scarborough, Department of Physical and } \\
\text { Environmental Sciences } \\
\text { Wania, Frank; University of Toronto Scarborough, Physical and } \\
\text { Environmental Sciences }\end{array}$ \\
\hline
\end{tabular}


1 The Effect of Sodium Sulfate, Ammonium Chloride, Ammonium Nitrate

2 and Salt Mixtures on Aqueous Phase Partitioning of Organic

3 Compounds

4 Chen Wang ${ }^{1}$, Ying Duan Lei ${ }^{1,2}$, Frank Wania ${ }^{1 *}$

$5{ }^{1}$ Department of Chemistry and Department of Physical and Environmental Sciences, University

6 of Toronto Scarborough, 1265 Military Trail, Toronto, Ontario, Canada M1C 1A4

$7 \quad{ }^{2}$ Department of Chemical Engineering and Applied Chemistry, University of Toronto

8 Scarborough, 1265 Military Trail, Toronto, Ontario, Canada M1C 1A4

9 *To whom correspondence should be addressed: frank.wania@utoronto.ca, +1-416-287-7225

10 TOC Art

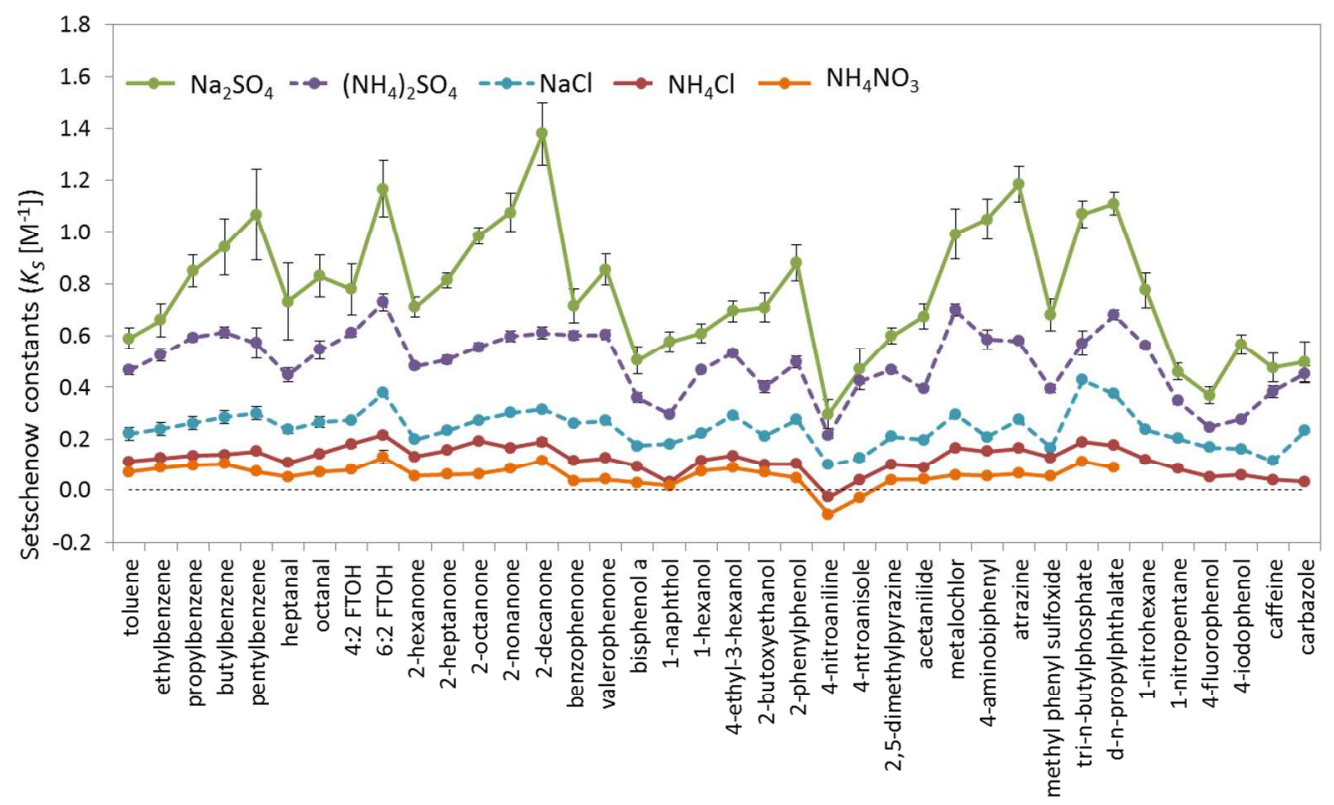




\section{Abstract}

13 Dissolved inorganic salt(s) influence the partitioning of organic compounds into the aqueous 14 phase. This influence is especially significant in atmospheric aerosol, which usually contains 15 large amount of ions, including sodium, ammonium, chloride, sulfate and nitrate. However, 16 empirical data on this salt effect are very sparse. Here, the partitioning of numerous organic compounds into solutions of $\mathrm{Na}_{2} \mathrm{SO}_{4}, \mathrm{NH}_{4} \mathrm{Cl}$ and $\mathrm{NH}_{4} \mathrm{NO}_{3}$ was measured and compared with existing data for $\mathrm{NaCl}$ and $\left(\mathrm{NH}_{4}\right)_{2} \mathrm{SO}_{4}$. Salt mixtures were also tested in order to establish whether the salt effect is additive. In general the salt effect showed a decreasing trend of $\mathrm{Na}_{2} \mathrm{SO}_{4}$ $>(\mathrm{NH})_{2} \mathrm{SO}_{4}>\mathrm{NaCl}>\mathrm{NH}_{4} \mathrm{Cl}>\mathrm{NH}_{4} \mathrm{NO}_{3}$ for the studied organic compounds, implying the following relative strength of the salt effect of individual anions: $\mathrm{SO}_{4}{ }^{2-}>\mathrm{Cl}^{-}>\mathrm{NO}_{3}{ }^{-}$and cations: $\mathrm{Na}^{+}>\mathrm{NH}_{4}{ }^{+}$. The salt effect of different salts is moderately correlated. Predictive models for the salt effect have been developed based on the experimental data. The experimental data indicate that the salt effect of mixtures may not be entirely additive. However, the deviation from additivity, if it exists, is small. Data of very high quality are required to establish whether the effect of constituent ions or salts is additive or not.

\section{Introduction}

28 In the environment, for example in atmospheric or sea water, a mixture of different inorganic salts is usually present. Important ions in atmospheric waters include $\mathrm{Na}^{+}, \mathrm{NH}_{4}^{+}, \mathrm{SO}_{4}{ }^{2-}, \mathrm{NO}_{3}{ }^{-}$, and $\mathrm{Cl}^{-}$, originating from both natural (e.g. sodium chloride from sea spray) and anthropogenic sources (e.g. nitrate and sulfate from $\mathrm{NO}_{\mathrm{X}}$ and $\mathrm{SO}_{2}$ ). The ionic strength in atmospheric aqueous phases varies with liquid water content, and ranges from $10^{-4} \mathrm{M}$ for dilute cloud, fog, and rain droplets to $>10 \mathrm{M}$ for deliquescent aerosol particles. ${ }^{1}$ Salts are also present in other aqueous systems, e.g. in brine pockets occurring in growing sea ice, in wastewater from the oil and gas extraction industry or in fresh water systems impacted by road salt applications. The presence of dissolved inorganic salt(s) has an effect on an organic compound's partitioning into the aqueous

37 phase, i.e., its solubility or activity coefficient in water. This is known as the salt effect and can be described by the Setschenow equation: ${ }^{2,3}$

where $K_{1 / \text { saltwater }}$ and $K_{1 / \text { water }}$ are partitioning coefficients of an organic compound between a non-

41 aqueous phase 1 and a salt solution or water, $K_{S}$ is the Setschenow or salting constant $\left(\mathrm{L} \mathrm{mol}^{-1}\right)$, 
42 and $C_{\text {salt }}$ is the concentration of the salt solution $\left(\mathrm{mol} \mathrm{L}^{-1}\right)$. There is a salting out effect when $K_{S}$ is

43 positive and a salting in effect when it is negative. The term $\log \left(K_{1 / \text { saltwater }} / K_{1 / \text { water }}\right)$ describes the

44 degree of salting out or salting in at the concentration $C_{\text {salt }}$.

45 While it is important to understand the influence of individual ions and salt mixtures on phase 46 partitioning and solubility of organic compounds in the aqueous phase, the natural association of 47 anions with cations makes it difficult to measure the salt effect of individual ions. Instead, we 48 can measure and compare the effect of different salts on an organic compound's solubility and 49 partitioning, and eventually compare the effect of individual ions indirectly. Endo et al. ${ }^{4}$ and 50 Wang et al. ${ }^{5}$ measured the salting out of a large variety of organic compounds from $\mathrm{NaCl}$ and $51(\mathrm{NH})_{2} \mathrm{SO}_{4}$ solutions, respectively, and developed poly-parameter linear free energy relationships 52 (pp-LFERs) for the prediction of Setschenow constants of these two salts. While these data sets 53 allow for a systematic comparison of the effect of these two salts, data for other salts are sparse. ${ }^{6-}$

$54{ }^{10}$ In particular, the empirical database is too small to derive information on the relative salt 55 effect of individual ions for a larger set of compounds. Furthermore, except for the group 56 contribution methods based on UNIFAC ${ }^{11,12}$ and AIOMFAC ${ }^{13}$ which predict activity coefficients 57 of chemical species in inorganic-organic mixtures, no models have been developed specifically 58 for the prediction of the effect for salts other than $\mathrm{NaCl}$ and $(\mathrm{NH})_{2} \mathrm{SO}_{4}$.

59 Little is known about the salt effect in salt mixtures, even though salts are usually present as 60 mixtures. To the best of our knowledge, the salt effect for salt mixtures has only been reported 61 for naphthalene at moderate ionic strengths in binary mixtures of $\mathrm{NaCl}$ with $\mathrm{MgCl}_{2}, \mathrm{Na}_{2} \mathrm{SO}_{4}$, $62 \mathrm{CaCl}_{2}, \mathrm{KBr}$ and $\mathrm{CsBr},{ }^{14}$ for fluorene and thiophene in $\mathrm{Na}-\mathrm{Ca}$ brines ${ }^{15}$ and for glyoxal in $63\left(\mathrm{NH}_{4}\right)_{2} \mathrm{SO}_{4}$ and $\mathrm{NH}_{4} \mathrm{NO}_{3}$ mixtures. ${ }^{10}$ With respect to whether the effect of multiple salts in a 64 mixed solution is additive, contradictory results have been found. The effect for naphthalene was 65 additive in inorganic salt mixtures, but non-additive if the mixtures contained organic salts. ${ }^{14}$ 66 Comparing two salts with one common ion, the effects of salts was found to be non-additive 67 (based on individual ions) for toluene ${ }^{16}$ but additive for benzene. ${ }^{17}$ Poulson et al. ${ }^{16}$ hypothesized 68 that toluene's dipole moment might allow for additional interactions in mixed electrolyte systems 69 that could cause the non-additive effect. However, the presence of a dipole moment in thiophene 70 had no effect on the additivity of $\mathrm{NaCl}$ and $\mathrm{CaCl}_{2}$ Setschenow constants. ${ }^{15}$ Clearly, the literature 71 on this issue is inconsistent and no general conclusion can be drawn from the small number of 72 studies that vary in terms of scope, quality and the treatment of uncertainty. Findings are 
73 generally qualified or their validity is limited to the specific salts and organic compounds being

74 studied.

75 A systematic and in-depth investigation of the salt effect of a large variety of organic compounds

76 in different salt solutions and salt mixtures is essential for understanding organic compound

77 behavior in complex aqueous solutions such as aerosol water, biological systems, brine water,

78 and industrial waste water. This topic has not been well studied despite both practical and

79 fundamental importance. One reason is the difficulty of these measurements. While it is often

80 challenging to accurately and precisely measure the water solubility of organic chemicals, ${ }^{18}$ it is

81 particularly difficult to precisely determine the relatively small difference in water solubility

82 caused by the salt effect. It is even more difficult to acquire such data with a quality and

83 precision that allows for an unequivocal assessment of the additivity of the salt effect. The

84 present study thus had the following objectives: (1) to determine and compare the salt effect for

85 different salts; (2) to test the additivity of the salt effect for salt solution mixtures as well as for

86 ions; (3) to develop and compare models for predicting Setschenow constants for different salts.

\section{Methods}

\section{Experimental Methods}

89 We measured $K_{\mathrm{S}}$ in solutions of $\mathrm{Na}_{2} \mathrm{SO}_{4}, \mathrm{NH}_{4} \mathrm{Cl}$, and $\mathrm{NH}_{4} \mathrm{NO}_{3}$ for the same group of 38 90 compounds with diverse functional groups as studied for $\mathrm{NaCl}$ by Endo et al. ${ }^{4}$ and for $\left(\mathrm{NH}_{4}\right)_{2} \mathrm{SO}_{4}$

91 by Wang et al. ${ }^{5}$ (Table 1). Salt effects in binary salt mixtures of 1:1 mole of $\mathrm{NaCl}$ and $\left(\mathrm{NH}_{4}\right)_{2} \mathrm{SO}_{4}$

92 were measured for selected compounds.

93 The shared headspace passive dosing (SHPD) method and the negligible depletion solid phase 94 micro extraction (SPME) method described in Endo et al. ${ }^{4}$ and Wang et al. ${ }^{5}$ were used to 95 measure the salt effect for different compounds (see detailed description of the experimental 96 methods in the supporting information). Table S1 in the supporting information indicates which 97 method was used for which compounds. Concentrations of the salt solutions, and the mixture 98 compositions are provided in Table S2. The salt solutions used in this study were not buffered 99 and their $\mathrm{pH}$ at different concentrations is given in Table S2. While $\mathrm{pH}$ might influence the salt 100 effect, it should be minor for the studied salts and organic compounds, because the latter are 101 primarily $(>99 \%)$ in their neutral form under the $\mathrm{pH}$ conditions of these salt solutions. The 102 exceptions are atrazine and 4-aminobiphenyl, which have a pKa of 1.7 and 4.35, respectively. ${ }^{19}$ 
103 Method for Testing Additivity

104 To test the additivity of the salt effects in a salt mixture we hypothesized that the following 105 equation should be valid if the effect is additive.

$106 \quad K_{s, \mathrm{mix}}=\sum_{i=1}^{n}\left(f_{i} K_{S, i}\right)$

107 where $f_{i}$ is the molar fraction of the $\mathrm{i}^{\text {th }}$ salt in the mixture, $K_{S, i}$ and $K_{S, m i x}$ are the Setschenow 108 constants of the $i^{\text {th }}$ salt and the salt mixture, respectively. In the specific case of a mixture of $109\left(\mathrm{NH}_{4}\right)_{2} \mathrm{SO}_{4}$ and $\mathrm{NaCl}$ tested here, equation 2 reads:

$110 K_{s, m i x}=f_{\mathrm{NaCl}} K_{S(\mathrm{NaCl})}+f_{(\mathrm{NH} 4) 2 \mathrm{SO} 4} K_{S(\mathrm{NH} 4) 2 \mathrm{SO} 4)}$

111 We also hypothesized that if the salt effect is additive for the ions in a solution, the following 112 equation should hold:

$113 K_{s, \text { salt }, i}=n_{\text {cation }} K_{S(\text { cation })}+n_{\text {anion }} K_{S(\text { anion })}$

114 where $K_{s, \text { salt }, i}$ is the Setschenow constant for salt $\mathrm{i}, n_{\text {cation }}$ and $n_{\text {anion }}$ are the numbers of cations and 115 anions in salt $\mathrm{i}$ and $K_{S(\text { cation })}$ and $K_{S(a n i o n)}$ are the Setschenow constants for the cation and anion, 116 respectively.

117 The additivity of the effect of ions can be tested by comparing salts with one common cation or 118 anion. For instance, by comparing the difference of $K_{S}$ between $\mathrm{NaCl}$ and $\mathrm{Na}_{2} \mathrm{SO}_{4}$, and between $119 \mathrm{NH}_{4} \mathrm{Cl}$ and $\left(\mathrm{NH}_{4}\right)_{2} \mathrm{SO}_{4}$, we can test whether the effect of a given salt is the sum of individual 120 contributions of the component ions for organic compound $j$. If individual ion effects are 121 additive, the difference in $K_{S}$ values between two salts with one common ion should be 122 independent of the identity of the common ion. For example, for the same organic compound we 123 would expect the difference in $K_{S}$ between $\mathrm{NaCl}$ and $\mathrm{NH}_{4} \mathrm{Cl}$ to be $1 / 2$ of the difference in $K_{S}$ 124 between $\mathrm{Na}_{2} \mathrm{SO}_{4}$ and $\left(\mathrm{NH}_{4}\right)_{2} \mathrm{SO}_{4}$.

$125 K_{S(\mathrm{Na} 2 \mathrm{SO} 4, \mathrm{j})}-K_{S(\mathrm{NH} 4) 2 \mathrm{SO} 4, \mathrm{j})}=2\left(K_{S(\mathrm{NaCl}, \mathrm{j})}-K_{S(\mathrm{NH} 4 \mathrm{Cl}, \mathrm{j}, \mathrm{j}}\right)$

126 Similarly, the difference between $K_{S(\mathrm{Na} 2 \mathrm{SO} 4, \mathrm{j})}$ and $2 K_{S(\mathrm{NaCl}, \mathrm{j})}$ should equal the difference between

$127 K_{S(\mathrm{NH} 4) 2 \mathrm{SO} 4, \mathrm{j})}$ and $2 K_{S(\mathrm{NH} 4 \mathrm{Cl}, \mathrm{j})}$.

$128 K_{S(\mathrm{Na} 2 \mathrm{SO} 4, \mathrm{j})}-2 K_{S(\mathrm{NaCl}, \mathrm{j})}=K_{S(\mathrm{NH} 4) 2 \mathrm{SO} 4, \mathrm{j})}-2 K_{S(\mathrm{NH} 4 \mathrm{Cl}, \mathrm{j})}$ 
129 An alternative approach is to compare whether the salt effect in mixtures of the same amount and 130 species of ions is equal by testing the validity of the following equation.

$131 K_{S(\mathrm{Na} 2 \mathrm{SO} 4, \mathrm{j})}+2 K_{S(\mathrm{NH} 4 \mathrm{Cl}, \mathrm{j})}=K_{S((\mathrm{NH} 4) 2 \mathrm{SO} 4, \mathrm{j})}+2 K_{S(\mathrm{NaCl}, \mathrm{j})}$

\section{Modeling Method}

133 The measured data are used to calibrate pp-LFERs for the prediction of $K_{S}$ in $\mathrm{Na}_{2} \mathrm{SO}_{4}, \mathrm{NH}_{4} \mathrm{NO}_{3}$, 134 and $\mathrm{NH}_{4} \mathrm{Cl}$ solutions. Specifically, multiple linear regressions yielded equations of the following 135 type:

$136 K_{S}=c+e E+s S+a A+b B+v V$

137 where $E, S, A, B$ and $V$ are solute descriptors representing a solute's excess molar refraction, 138 dipolarity/polarizability, hydrogen-bond acidity, hydrogen-bond basicity and McGowan volume $139\left(\mathrm{~cm}^{3} \mathrm{~mol}^{-1}\right)$ divided by 100 , respectively. Descriptors for the organic solutes studied here were 140 taken from the UFZ-LSER database ${ }^{20}$ and are listed in the supporting information (Table S3).

141 The regression coefficients are denoted by $a, b, s, e$ and $v ; c$ is the regression constant.

\section{Results and Discussion}

\section{Setschenow Coefficients in Different Salt Solutions}

144 The $K_{S}$ measured in different salt solutions are shown in Table 1 . The $K_{S}$ values for a few 145 compounds in $\mathrm{NH}_{4} \mathrm{NO}_{3}$ solutions are not reported, because a low salt effect made it difficult to 146 achieve high quality data. For comparison, the 2-ketones were measured with both methods; data 147 obtained with the SHPD method are in the supporting information (Table S4). Absolute 148 differences between the two methods are in the range of $0 \sim 0.024 \mathrm{~L} \mathrm{~mol}^{-1}$ for $\mathrm{NH}_{4} \mathrm{NO}_{3}$, $1490.012 \sim 0.053 \mathrm{~L} \mathrm{~mol}^{-1}$ for $\mathrm{NH}_{4} \mathrm{Cl}$ and $0.001 \sim 0.143 \mathrm{~L} \mathrm{~mol}^{-1}$ for $\mathrm{Na}_{2} \mathrm{SO}_{4}$, indicating generally good 150 agreement. We note however that the discrepancy between the two methods ( $\Delta K_{\mathrm{S}}$ in Table S4) is 151 sometimes larger than the reported precision of the $K_{\mathrm{S}}$ values (standard error, SE, in Tables 1 and 152 S4), which was derived as described in the Supporting Information. It is thus possible that the 153 random errors as expressed in the SE values in Tables 1 and S4 underestimate the true 154 uncertainty of the reported $K_{\mathrm{S}}$ values, i.e. there is the possibility of some bias.

155 In general, linear relationships (with high $\mathrm{R}^{2}$ and low $\mathrm{SE}$ of the linear regression in Table 1) 156 between the extent of the salt effect and the salt concentration were observed for all the measured 
157 organic compounds in the range of salt concentrations used in the study. This indicates that the 158 Setschenow equation (eq. 1) is valid for a wide variety and concentrations of salt solutions and 159 Setschenow coefficients (salting out/in coefficients) are constants up to the highest studied salt 160 concentrations (Table S2).

161 The measured $K_{S}$ values range from $0.296 \pm 0.057$ to $1.379 \pm 0.123$ for $\mathrm{Na}_{2} \mathrm{SO}_{4}$, from $162-0.027 \pm 0.007$ to $0.215 \pm 0.012$ for $\mathrm{NH}_{4} \mathrm{Cl}$ and from $-0.094 \pm 0.006$ to $0.130 \pm 0.026$ for $\mathrm{NH}_{4} \mathrm{NO}_{3}$ (in 163 unit of $\left.\mathrm{L} \mathrm{mol}^{-1}\right)$. Pentylbenzene (0.176), heptanal (0.146) and 2-decanone (0.123) have the 164 highest $\mathrm{SE}$ for $\mathrm{Na}_{2} \mathrm{SO}_{4}$, indicating less precise results. 6:2 FTOH and 2-decanone have the 165 highest $\mathrm{SE}$ for $\mathrm{NH}_{4} \mathrm{Cl}(0.012$ and 0.015$)$ and $\mathrm{NH}_{4} \mathrm{NO}_{3}(0.026$ and 0.010$)$. A relatively large $\mathrm{SE}$ 166 can occur when quantification is challenged by a compound's low concentration/solubility in salt 167 solutions (e.g. 2-decanone, pentylbenzene, and 6:2 FTOH). The relatively large SEs for 6:2 168 FTOH may be due to its relatively high volatility, which may cause loss during sampling of the 169 aqueous solutions using a syringe.

170 Among all the measured compounds, 4-nitroaniline had the lowest $K_{S}$ in different salt solutions, 171 including in $\mathrm{NaCl}$ and $\left(\mathrm{NH}_{4}\right)_{2} \mathrm{SO}_{4}$. In $\mathrm{NH}_{4} \mathrm{NO}_{3}$ and $\mathrm{NH}_{4} \mathrm{Cl}$ solutions 4-nitroaniline was found to 172 salt in $\left(K_{S}<0\right)$; 4-nitroanisole did the same in $\mathrm{NH}_{4} \mathrm{NO}_{3}$ solutions. These two compounds are 173 relatively polar, a structural attribute that has previously been identified as causing a low salting 174 out effect. ${ }^{4,5}$ In another study, nitrobenzaldehyde was found to salt into solutions of nitrate salts,

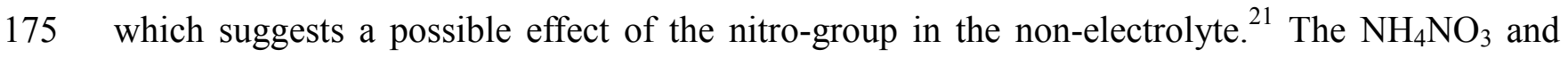
$176 \mathrm{NH}_{4} \mathrm{Cl}$ solutions are both acidic, which might alter the electron distribution of the nitro-group 177 and render the organic compounds containing nitro-groups more polar, causing it to salt in under 178 acidic conditions. Others also observed a salting in effect for polar compounds such as glyoxal 179 and amino acids. ${ }^{10,22,23}$ Other than 4-nitroaniline and 4-nitroanisole, the studied compounds all 180 had positive $K_{S}$ values in different salt solutions.

181 Comparison with earlier studies is difficult due to the dearth of literature data, with only toluene 182 having been previously measured in $\mathrm{Na}_{2} \mathrm{SO}_{4}$ and $\mathrm{NH}_{4} \mathrm{Cl}$, $, 9,24$ ethylbenzene and propylbenzene 183 in $\mathrm{Na}_{2} \mathrm{SO}_{4}{ }^{9}$ and 1-naphthol in $\mathrm{NH}_{4} \mathrm{Cl}^{25}$ Table S5 compares $K_{S}$ reported in the literature with the 184 values measured here. The generally small differences (absolute difference between 0.033 and 1850.1 for $\mathrm{Na}_{2} \mathrm{SO}_{4}$ and between 0.024 and 0.071 for $\mathrm{NH}_{4} \mathrm{Cl}$ ) are acceptable in light of uncertainties 186 in the experimental and analytical methods from different studies. 
187 Table $1 \quad$ Setschenow constants $\left(K_{S}\left[\mathrm{~L} \mathrm{~mol}^{-1}\right]\right)$ for organic compounds in different salt

\begin{tabular}{|c|c|c|c|c|c|c|c|c|c|c|c|}
\hline & \multicolumn{3}{|c|}{$\mathrm{NH}_{4} \mathrm{NO}_{3}$} & \multicolumn{3}{|c|}{$\mathrm{NH}_{4} \mathrm{Cl}$} & \multicolumn{3}{|c|}{$\mathrm{Na}_{2} \mathrm{SO}_{4}$} & \multirow{2}{*}{$\begin{array}{c}\left(\mathrm{NH}_{4}\right)_{2} \mathrm{SO}_{4}{ }^{\mathrm{a}} \\
\mathrm{K}_{\mathrm{S}} \\
\end{array}$} & \multirow{2}{*}{$\begin{array}{c}\mathrm{NaCl}^{\mathrm{b}} \\
\mathrm{K}_{\mathrm{S}} \\
\end{array}$} \\
\hline & $\mathrm{K}_{\mathrm{S}}$ & $\mathrm{SE}^{\mathrm{c}}$ & $\mathrm{R}^{2 \mathrm{c}}$ & $\mathrm{K}_{\mathrm{S}}$ & SE & $\mathrm{R}^{2}$ & $\mathrm{~K}_{\mathrm{S}}$ & SE & $\mathrm{R}^{2}$ & & \\
\hline toluene & 0.071 & 0.006 & 0.95 & 0.112 & 0.005 & 0.98 & 0.590 & 0.040 & 0.96 & 0.465 & 0.221 \\
\hline ethylbenzene & 0.088 & 0.006 & 0.96 & 0.126 & 0.009 & 0.95 & 0.660 & 0.062 & 0.93 & 0.525 & 0.238 \\
\hline n-propylbenzene & 0.097 & 0.006 & 0.97 & 0.135 & 0.010 & 0.95 & 0.848 & 0.060 & 0.96 & 0.594 & 0.262 \\
\hline n-butylbenzene & 0.103 & 0.005 & 0.98 & 0.140 & 0.010 & 0.96 & 0.940 & 0.109 & 0.89 & 0.614 & 0.285 \\
\hline pentylbenzene & 0.072 & 0.005 & 0.96 & 0.153 & 0.006 & 0.99 & 1.067 & 0.176 & 0.80 & 0.572 & 0.300 \\
\hline heptanal & 0.051 & 0.009 & 0.83 & 0.107 & 0.012 & 0.92 & 0.732 & 0.146 & 0.71 & 0.447 & 0.237 \\
\hline octanal & 0.071 & 0.009 & 0.87 & 0.143 & 0.007 & 0.97 & 0.829 & 0.081 & 0.91 & 0.545 & 0.265 \\
\hline $4: 2 \mathrm{FTOH}$ & 0.080 & 0.005 & 0.96 & 0.181 & 0.010 & 0.98 & 0.778 & 0.096 & 0.87 & 0.611 & 0.273 \\
\hline 6:2 FTOH & 0.130 & 0.026 & 0.83 & 0.215 & 0.012 & 0.98 & 1.166 & 0.109 & 0.92 & 0.729 & 0.378 \\
\hline 2-hexanone & 0.056 & 0.003 & 0.98 & 0.131 & 0.008 & 0.97 & 0.710 & 0.038 & 0.98 & 0.481 & 0.198 \\
\hline 2-heptanone & 0.060 & 0.004 & 0.97 & 0.157 & 0.008 & 0.98 & 0.812 & 0.027 & 0.99 & 0.506 & 0.228 \\
\hline 2-octanone & 0.063 & 0.005 & 0.95 & 0.193 & 0.004 & 1.00 & 0.983 & 0.032 & 0.99 & 0.556 & 0.267 \\
\hline 2-nonanone & 0.083 & 0.005 & 0.97 & 0.167 & 0.006 & 0.98 & 1.075 & 0.075 & 0.96 & 0.598 & 0.306 \\
\hline 2-decanone & 0.117 & 0.010 & 0.93 & 0.188 & 0.015 & 0.94 & 1.379 & 0.123 & 0.94 & 0.612 & 0.321 \\
\hline benzophenone & 0.037 & 0.006 & 0.85 & 0.114 & 0.004 & 0.99 & 0.715 & 0.065 & 0.94 & 0.602 & 0.262 \\
\hline valerophenone & 0.041 & 0.005 & 0.90 & 0.125 & 0.005 & 0.98 & 0.854 & 0.061 & 0.96 & 0.604 & 0.271 \\
\hline bisphenol a & 0.028 & 0.003 & 0.84 & 0.094 & 0.008 & 0.91 & 0.504 & 0.055 & 0.87 & 0.359 & 0.174 \\
\hline 1-naphthol & 0.018 & 0.004 & 0.69 & 0.030 & 0.007 & 0.65 & 0.576 & 0.038 & 0.95 & 0.297 & 0.182 \\
\hline 1-hexanol & 0.075 & 0.002 & 0.99 & 0.115 & 0.002 & 0.99 & 0.610 & 0.035 & 0.97 & 0.466 & 0.221 \\
\hline 4-ethyl-3-hexanol & 0.087 & 0.004 & 0.97 & 0.135 & 0.005 & 0.98 & 0.695 & 0.039 & 0.96 & 0.533 & 0.291 \\
\hline 2-butoxyethanol & 0.069 & 0.005 & 0.92 & 0.102 & 0.005 & 0.96 & 0.709 & 0.054 & 0.93 & 0.400 & 0.211 \\
\hline 2-phenylphenol & 0.047 & 0.004 & 0.94 & 0.102 & 0.007 & 0.95 & 0.879 & 0.068 & 0.95 & 0.496 & 0.274 \\
\hline 4-nitroaniline & -0.094 & 0.006 & 0.95 & -0.027 & 0.007 & 0.53 & 0.296 & 0.057 & 0.68 & 0.216 & 0.099 \\
\hline 4-ntroanisole & -0.028 & 0.005 & 0.73 & 0.039 & 0.003 & 0.95 & 0.469 & 0.081 & 0.79 & 0.423 & 0.126 \\
\hline 2,5-dimethylpyrazine & 0.040 & 0.003 & 0.94 & 0.102 & 0.004 & 0.98 & 0.600 & 0.031 & 0.97 & 0.467 & 0.209 \\
\hline acetanilide & 0.042 & 0.007 & 0.74 & 0.090 & 0.006 & 0.95 & 0.674 & 0.049 & 0.93 & 0.393 & 0.197 \\
\hline metalochlor & 0.060 & 0.007 & 0.84 & 0.166 & 0.007 & 0.98 & 0.992 & 0.097 & 0.92 & 0.699 & 0.296 \\
\hline 4-aminobiphenyl & 0.056 & 0.006 & 0.87 & 0.152 & 0.008 & 0.97 & 1.049 & 0.077 & 0.95 & 0.585 & 0.208 \\
\hline atrazine & 0.065 & 0.005 & 0.94 & 0.164 & 0.006 & 0.98 & 1.184 & 0.068 & 0.97 & 0.581 & 0.274 \\
\hline methyl phenyl sulfoxide & 0.053 & 0.005 & 0.89 & 0.128 & 0.011 & 0.92 & 0.681 & 0.061 & 0.91 & 0.393 & 0.166 \\
\hline tri-n-butylphosphate & 0.112 & 0.007 & 0.96 & 0.188 & 0.005 & 0.99 & 1.069 & 0.051 & 0.98 & 0.571 & 0.428 \\
\hline d-n-propylphthalate & 0.087 & 0.004 & 0.97 & 0.176 & 0.005 & 0.99 & 1.108 & 0.044 & 0.99 & 0.680 & 0.374 \\
\hline 1-nitrohexane & 0.026 & 0.007 & 0.69 & 0.120 & 0.006 & 0.97 & 0.775 & 0.066 & 0.93 & 0.561 & 0.236 \\
\hline 1-nitropentane & NA & NA & NA & 0.084 & 0.004 & 0.98 & 0.459 & 0.033 & 0.95 & 0.347 & 0.203 \\
\hline 4-fluorophenol & NA & NA & NA & 0.051 & 0.004 & 0.91 & 0.369 & 0.031 & 0.92 & 0.246 & 0.168 \\
\hline 4-iodophenol & NA & NA & NA & 0.059 & 0.004 & 0.95 & 0.566 & 0.039 & 0.94 & 0.276 & 0.162 \\
\hline caffeine & NA & NA & NA & 0.040 & 0.004 & 0.86 & 0.476 & 0.055 & 0.84 & 0.383 & 0.114 \\
\hline carbazole & NA & NA & NA & 0.032 & 0.003 & 0.91 & 0.499 & 0.080 & 0.81 & 0.452 & 0.232 \\
\hline
\end{tabular}

$189{ }^{a}$ measurements by Wang et al., ${ }^{5}$ b measurements by Endo et al., ${ }^{4}$ c Standard Error (SE) and coefficient of 190 determination $\left(\mathrm{R}^{2}\right)$ of a linear regression between the extent of the salt effect (represented by $\log \left(K_{\text {I/salt water }} / K_{1 / \text { water }}\right)$, 191 and the salt concentration. 
192 Comparison and Correlation of $K_{S}$ for Different Salts

193 For all organic compounds measured in this study, we find a general trend in the magnitude of 194 the salt effect, namely a sequence of decreasing $K_{S}$ according to: $\mathrm{Na}_{2} \mathrm{SO}_{4}>\left(\mathrm{NH}_{4}\right)_{2} \mathrm{SO}_{4}>\mathrm{NaCl}>$ $195 \mathrm{NH}_{4} \mathrm{Cl}>\mathrm{NH}_{4} \mathrm{NO}_{3}$. This order also applies for the two compounds with a salting in effect. This 196 indicates very distinct salt effects of different salts on a given organic compound and the same 197 order of salt effect for various organic compounds despite their different size, functional groups 198 and polarity. The salts with a doubly charged anion $\left(\mathrm{SO}_{4}{ }^{2-}\right)$ have a larger salting out effect, which 199 agrees with findings in other studies. ${ }^{7,8,26}$ For the same cation $\left(\mathrm{Na}^{+}\right.$or $\left.\mathrm{NH}_{4}{ }^{+}\right), \mathrm{SO}_{4}{ }^{2-}$ salts have a 200 higher salting out effect than $\mathrm{Cl}^{-}$salts, while for the same anion $\left(\mathrm{Cl}^{-}\right.$or $\left.\mathrm{SO}_{4}{ }^{2-}\right), \mathrm{Na}^{+}$salts always 201 have a higher salting out effect than $\mathrm{NH}_{4}{ }^{+}$salts, in agreement with previous studies for other 202 compounds. ${ }^{7,8,26} \mathrm{NO}_{3}{ }^{-}$tends to have the lowest salting out effect among all studied anions. Both 203 Görgényi et al. ${ }^{7}$ and Waxman et al. ${ }^{10}$ reported nitrate salts having the lowest salting out effect 204 among anions. In this study, the trend of salt effect by different salts was observed for a large variety of organic compounds. The order of the salt effect by different anions agrees with the Hofmeister series, which ranks the relative influence of ions on the physical behavior of a wide variety of aqueous processes for protein. ${ }^{27,28}$ The average coefficient of variation for $K_{S}$ among different organic compounds for one salt (ranging from 0.29 to 0.70 with an average of 0.41 ) is smaller than that among all the salts for an individual compound (ranging from 0.60 to 1.66 with an average of 0.88). Overall, this indicates that the extent of the salt effect is largely determined by the salt species but also varies for different organic compounds.

212 The $K_{S}$ for each pair of salts are significantly correlated, as shown in Figure S3, with correlation 213 coefficients $(r)$ between 0.703 and $0.861 \quad(p<0.01)$. Such correlations had previously been 214 observed between $\mathrm{NaCl}$ and $\left(\mathrm{NH}_{4}\right)_{2} \mathrm{SO}_{4},{ }^{5}$ between $\mathrm{NaCl}$ and $\mathrm{KCl}$, and between $\mathrm{NaCl}$ and

$215 \mathrm{CaCl}_{2} \cdot{ }^{15}$ The observation that the salt effect follows a specific order and $K_{S}$ for different salts are 216 significantly correlated suggests that the identity of the salts determines the order of the salt 217 effect (ion-water interaction), while the identity of the organic solutes determines its specific 218 value (organic-water or organic-ion interaction). The $K_{S}$ for a specific compound is largely 219 determined by the salt species' properties. The variability in the effect of different salts has been 220 proposed to be related to the varying structure, size, charge density, hydration and dielectric 221 constant of their constituent ions. ${ }^{29}$ To a lesser extent, it also depends on the organic compound's 222 properties. Previous work identified size/volume and polarity of an organic solute as influencing 
223 its $K_{S}{ }^{4-6,30,31}$ The consistent salting order among different salts confirms that the organic 224 molecular size and polarity only change the overall magnitude of the salt effect without greatly 225 affecting the variations among different salt species.

226 The multitude of intermolecular interactions involving various combinations of ions, organic 227 solutes and solvents (usually water) renders the salt effect very complex. As discussed above, the 228 magnitude and direction of the effect of a salt on an organic solute in solution depends on the 229 properties of both salt and solute. Several qualitative and quantitative theories and mechanisms 230 of the salt effect have been presented. While they can explain some aspects of the salt effect, 231 none of these theories appears capable of explaining all of the observations. Long and McDevit ${ }^{30}$ 232 and Grover and Ryall ${ }^{29}$ reviewed those theories thoroughly. In the following, we attempt to 233 explain the relative order of the salt effect for different salts based on some of those theories.

234 According to the hydration theory, the formation of hydration shells around ionic species 235 effectively reduces the availability of free water molecules for solvating organic compounds, 236 thus leading to a salting out effect. The magnitude of the salt effect has been related to the charge 237 density (valency per ionic volume) of the corresponding ions: ions with a bigger charge density 238 have larger hydration shells, and thus exhibit a stronger salting-out effect. ${ }^{8}$ A similar theory 239 based on the Born equation ${ }^{32}$ relates $K_{S}$ with the square of the charge of the ion $\left(\mathrm{z}^{2}\right)$ and the 240 reciprocal of the radius of the ion (r). ${ }^{33}$ The Born equation calculates the Gibbs free energy of 241 solvation $\left(\Delta \mathrm{G}_{\mathrm{solv}}\right)$, i.e. the energy of hydration $\left(\Delta \mathrm{G}_{\mathrm{hyd}}\right)$ in the case of water as solvent, which is 242 negatively proportional to $\mathrm{z}^{2} / \mathrm{r}$. The lower $\Delta \mathrm{G}_{\text {hyd }}$ indicates a stronger interaction of ion with 243 water, thus a higher salting out effect. ${ }^{34}$ The sequence in $\mathrm{z}^{2} / \mathrm{r}$ is $\mathrm{SO}_{4}{ }^{2-}>\mathrm{Cl}^{-} \approx \mathrm{NO}_{3}{ }^{-}$for the anions, 244 and $\mathrm{Na}^{+}>\mathrm{NH}_{4}{ }^{+}$for the cations (Table S6) and thus follows the same trend as the measured salt 245 effect, except for $\mathrm{NO}_{3}{ }^{-}$, which exhibits a lower $K_{S}$ than would be expected based on this theory. 246 The sequence in $\Delta \mathrm{G}_{\text {hyd }}$ from the literature (Table S6) is $\mathrm{SO}_{4}{ }^{2-}>\mathrm{Cl}^{-}>\mathrm{NO}_{3}{ }^{-}$for the anions, and

$247 \mathrm{Na}^{+}>\mathrm{NH}_{4}{ }^{+}$for the cations, in agreement with the trend of the salt effect.

248 pp-LFERs Development

249 The theoretical understanding of the salt effect is currently insufficient to make quantitative 250 predictions. Therefore, prediction methods based on the regression of empirical data have an 251 important role to play. The experimental data from this study were used to calibrate the 252 following pp-LFERs for $K_{\mathrm{S}}$ in solutions of $\mathrm{Na}_{2} \mathrm{SO}_{4}, \mathrm{NH}_{4} \mathrm{Cl}$ and $\mathrm{NH}_{4} \mathrm{NO}_{3}$ : 
$253 \quad K_{\mathrm{S}}\left(\mathrm{Na}_{2} \mathrm{SO}_{4}\right)=0.339( \pm 0.125)-0.022( \pm 0.073)$ E- 0.120( \pm 0.110$) S-0.289( \pm 0.106) A-$

$K_{\mathrm{S}}\left(\mathrm{NH}_{4} \mathrm{Cl}\right)=0.054( \pm 0.022)-0.018( \pm 0.013)$ E- 0.039( \pm 0.020$) S-0.043( \pm 0.019) A-$

$257 \quad K_{\mathrm{S}}\left(\mathrm{NH}_{4} \mathrm{NO}_{3}\right)=0.048( \pm 0.022)-0.013( \pm 0.013) \mathrm{E}-0.060( \pm 0.020) S-0.001( \pm 0.020) A-$

There are fewer measured data available for $\mathrm{NH}_{4} \mathrm{NO}_{3}$ due to experimental challenges. Thus, the pp-LFER developed for $\mathrm{NH}_{4} \mathrm{NO}_{3}$ in this study has a smaller application domain. The relative large and positive values of $v$, and relative small and negative values of $e, s, a$, and $b$ agree with previous pp-LFERs for the $K_{\mathrm{S}}$ in $\mathrm{NaCl}$ and $\left(\mathrm{NH}_{4}\right)_{2} \mathrm{SO}_{4}$ solutions, ${ }^{4} 5$ suggesting a large and positive influence of molecular volume and a small and negative influence of polar interactions on $K_{S}$. The absolute values of the regression coefficients of the pp-LFER for $\mathrm{Na}_{2} \mathrm{SO}_{4}$ are the highest among all the five pp-LFERs, followed by those for $\left(\mathrm{NH}_{4}\right)_{2} \mathrm{SO}_{4}$ and $\mathrm{NaCl}$. The pp-LFERs for $\mathrm{NH}_{4} \mathrm{NO}_{3}$ and $\mathrm{NH}_{4} \mathrm{Cl}$ have the smallest absolute regression coefficients. The $\mathrm{R}^{2}$ and standard deviation (SD) of the pp-LFERs calibrated for $\mathrm{Na}_{2} \mathrm{SO}_{4}, \mathrm{NH}_{4} \mathrm{Cl}$ and $\mathrm{NH}_{4} \mathrm{NO}_{3}$ are not as good as in the pp-LFERs for $\mathrm{NaCl}$ and $\left(\mathrm{NH}_{4}\right)_{2} \mathrm{SO}_{4}$. For all pp-LFERs, there is a significant positive correlation of $V$ with $K_{S}(\mathrm{p}<0.05)$. However, the other regression coefficients $(a, b, s$ and $e)$ are not always significant. Parameter $a$ was only significant for $K_{\mathrm{S}}\left(\mathrm{Na}_{2} \mathrm{SO}_{4}\right)$ and $K_{\mathrm{S}}\left(\mathrm{NH}_{4} \mathrm{Cl}\right)$ and $s$ for $K_{\mathrm{S}}\left(\mathrm{NH}_{4} \mathrm{NO}_{3}\right)$. It is likely that the salt effect arises primarily from differences in the behavior of

272 the particular salt solutions toward the "cavity" created by the organic molecule (which is 273 determined by the size of the molecule), and that polar interactions, if present, have a modifying 274 influence.

275 If we retain only the solute descriptors whose contribution to the variability in $K_{\mathrm{S}}$ was 276 significant, we obtain the following pp-LFERs:

$K_{\mathrm{S}}\left(\mathrm{Na}_{2} \mathrm{SO}_{4}\right)=0.400( \pm 0.113)-0.185( \pm 0.060) S-0.263( \pm 0.101) A+0.461( \pm 0.077) V$

$278 \quad\left(n=38, R^{2}=0.605, \mathrm{SD}=0.165\right)$

$280 \quad\left(n=38, R^{2}=0.709, \mathrm{SD}=0.030\right)$ 
$K_{\mathrm{S}}\left(\mathrm{NH}_{4} \mathrm{NO}_{3}\right)=0.053( \pm 0.020)-0.076( \pm 0.011) S+0.059( \pm 0.014) \mathrm{V}$

$283 K_{S}$ for compounds measured in this study and in the literature (Table S5 and S7) are compared 284 with values predicted from the calibrated pp-LFERs (equations 12 to 14) (Figure 1). The 285 predictions generally agree well with the measurement, with a root-mean-square error (RMSE) 286 of $0.028,0.028$ and $0.133 \mathrm{~L} \mathrm{~mol}^{-1}$ for $\mathrm{NH}_{4} \mathrm{NO}_{3}, \mathrm{NH}_{4} \mathrm{Cl}$ and $\mathrm{Na}_{2} \mathrm{SO}_{4}$ for all the measured data, 287 and a RMSE of $0.027,0.028$ and $0.078 \mathrm{~L} \mathrm{~mol}^{-1}$ for literature data only.
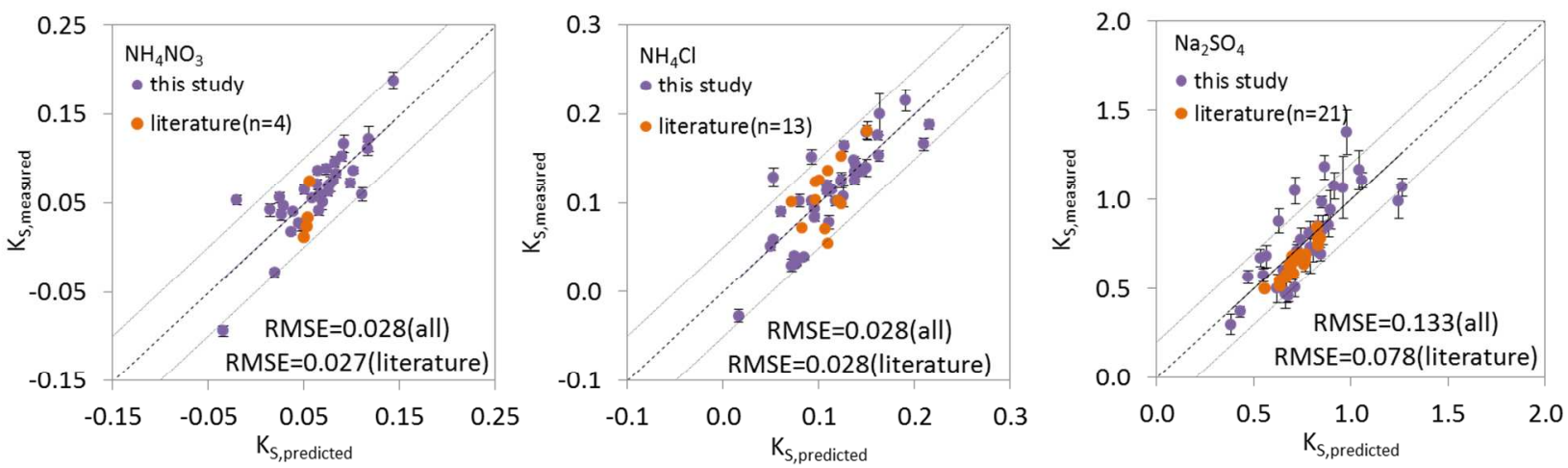

Figure 1

It is important to recognize that a $K_{\mathrm{S}}$ predicted by ppLFER quantifies only the effect of a salt on the aqueous solvation of an organic compound, and can thus not be expected to predict the "effective" salting behavior of compounds that undergo additional reactions within an aqueous salt solution. For example, there has been evidence that sulfate could modify the hydration equilibrium of glyoxal and both ammonium and sulfate may react with glyoxal. ${ }^{35}$ A ppLFER can thus not describe the combined effect of hydration, reaction and salt effect that is observed experimentally. ${ }^{10}$

Among the measured compounds, there are two groups of compounds that differ only by the number of methylene (- $\left.\mathrm{CH}_{2}-\right)$ group, namely the 2-ketones and alkylbenzenes. The similarity of

301 their structures provides an opportunity to analyze the influence of molecular size on $K_{S}$. 302 Generally, with increasing number of methylene group in the molecule (also an increase of 303 volume), $K_{S}$ increases linearly for both groups of compounds (Figure S4). The increments of $K_{S}$ 
304 with an increasing number of methylene and with increasing McGowan volume are illustrated by 305 the slopes of the linear regressions in Figure S4. The increments of $K_{S}$ for the 2-ketones are 306 significantly larger than for the alkylbenzenes ( $<<0.05$, analysis of covariance), but in both cases 307 they are in the same order as the general trend of the salting out effect: $\mathrm{Na}_{2} \mathrm{SO}_{4}>\left(\mathrm{NH}_{4}\right)_{2} \mathrm{SO}_{4}>$ $308 \mathrm{NaCl}>\mathrm{NH}_{4} \mathrm{Cl} \approx \mathrm{NH}_{4} \mathrm{NO}_{3}$. It is difficult to differentiate the increments for $K_{\mathrm{S}}\left(\mathrm{NH}_{4} \mathrm{Cl}\right)$ and $309 K_{\mathrm{S}}\left(\mathrm{NH}_{4} \mathrm{NO}_{3}\right)$ because the $K_{S}$ values are relatively small. The different increments for the two 310 groups of compounds suggest an influence of the structure of the compounds. The $\mathrm{R}^{2}$ of the 311 linear regression in Figure S4 also indicates that the McGowan volume alone can explain 83\%$31298 \%$ of the variation between the $K_{\mathrm{S}}$ values for 2 -ketones and $64 \%-98 \%$ of the variation for the 313 alkylbenzenes in different salt solutions.

\section{Additivity of Ions in Salt Solutions}

315 The additivity of the effects of ions in solution was tested through equations (5) to (7), which 316 compare $K_{S}$ for two salts with a common ion. In addition to the 38 compounds measured in this 317 study, literature data were also included for comparison (listed in Table S7). Figure 2 plots the 318 terms on either side of equations (5) to (7) against each other (the data are provided in Table S8). 319 A data point falls on the 1:1 line, if the effect of ions is perfectly additive for an organic solute. A 320 paired t-test was used to test whether the average of the difference between the terms on both 321 sides of equations (5) to (7) is significantly different from zero. The paired t-test indicated no 322 significant difference between the values on either side of the equations $(p>0.05)$ for the data 323 generated in this study and for all data including literature values, suggesting that there is not 324 sufficient evidence to indicate that the salt effect is not additive with respect to the individual 325 ions. Literature data sufficiently accurate to test additivity with statistical rigor had not been 326 available in the past. Earlier results reported for benzene and toluene had been contradictory (i.e. 327 additive for benzene but non-additive for toluene). ${ }^{16,}{ }^{17}$ Note that the values for any one 328 compound in Table S8 may not indicate additivity, i.e., not all points fall on the 1:1 line in Figure 329 2. This means the additivity of the effect of ions may not apply for all compounds. However, 330 these points do not change the result of the statistical analysis since the t-test is comparing the 331 overall agreement. 

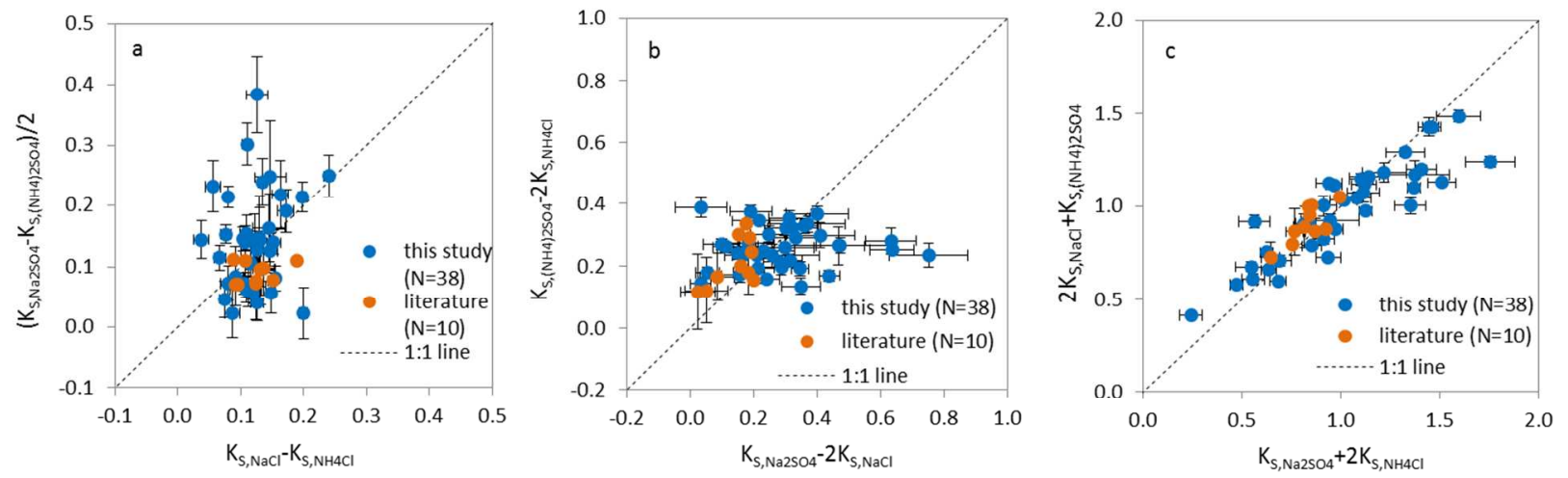
each individual salt.

\section{Additivity in Salt Mixtures}

336 The salting out of the five 2-ketones from solutions containing different concentrations of a 337 mixture of $\mathrm{NaCl}$ and $\left(\mathrm{NH}_{4}\right)_{2} \mathrm{SO}_{4}$ (1:1 on a molar basis) was measured with both SPME and 338 SHPD methods. As in single salt solutions, linear relationships between $\log \left(\mathrm{K}_{1 / \text { salt water }} / \mathrm{K}_{1 / \text { water }}\right)$ and salt concentrations were observed (Figure 3), allowing Setschenow coefficients in salt mixtures $\left(K_{S, m i x}\right)$ to be derived from their slopes. Error bars in Figure 3 illustrate the deviation among four experimental replicates. To test the additivity of the salting out effect, Figure 3 compares this observed effect (blue squares) with a calculated additive effect (red squares), obtained using equation 2, and the $K_{S}$ for $\mathrm{NaCl}$ and $\left(\mathrm{NH}_{4}\right)_{2} \mathrm{SO}_{4}$ from Endo et al. ${ }^{4}$ and Wang et al., ${ }^{5}$ respectively.

345 Both the observed and the calculated $K_{S, m i x}$ fall between the $K_{S}$ for $\mathrm{NaCl}$ (orange circles) and $346\left(\mathrm{NH}_{4}\right)_{2} \mathrm{SO}_{4}$ (purple circles). Even though they are generally quite close to each other, the 347 calculated $K_{S, m i x}$ values are consistently higher than the observed ones for all five compounds

348 (Figure 3), suggesting lower than additive salting out from salt mixtures. In order to test whether 349 the difference between observed and calculated $K_{S, m i x}$ is significant or not, we applied analysis of 350 covariance to compare the slopes of the two linear regressions. The results suggest that within 351 the uncertainty of the measurements, the salting out effect is additive for 2-hexanone and 2352 heptanone ( $\mathrm{p}>0.05$, i.e. the two slopes not significant different) but not additive for the other 353 three compounds $(\mathrm{p}<0.05)$. Some of the observed values have relatively large uncertainty, 354 because it is difficult to precisely quantify small amounts of sparingly soluble substances sorbed 
355 to the SPME fibers. For instance, the data for 2-decanone at $3 \mathrm{M}$ was excluded in the regression 356 analysis due to large uncertainty.
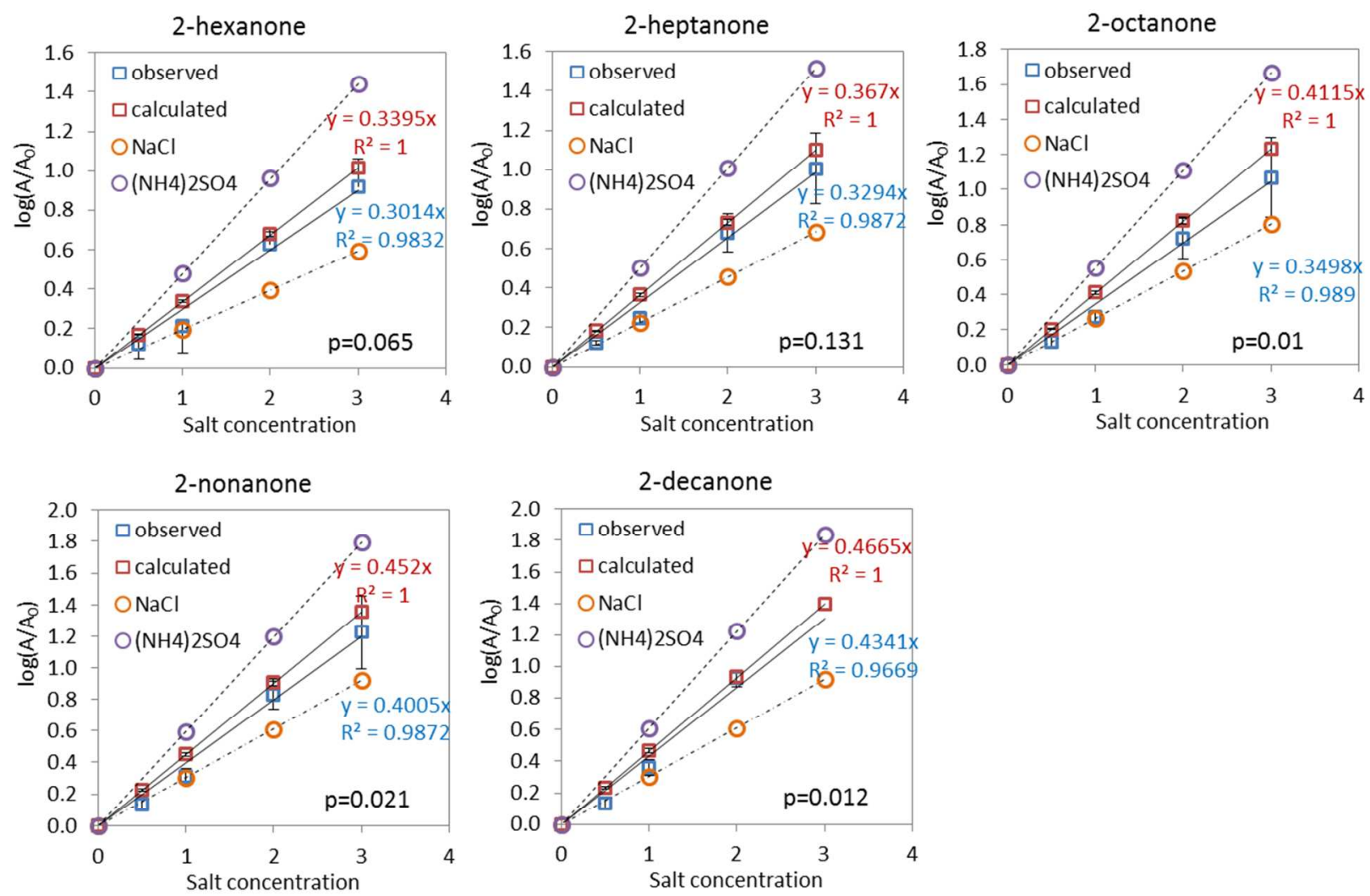

Figure 3 Salting out effect in salt mixtures (1: 1 mole ratio $\mathrm{NaCl}$ and $\left.\left(\mathrm{NH}_{4}\right)_{2} \mathrm{SO}_{4}\right)$ measured using the SPME method. The degree of salting out, i.e., $\log \left(\mathrm{K}_{1 / \text { salt water }} / \mathrm{K}_{1 / \text { water }}\right)$, was calculated from the logarithm of the ratio between GC peak areas of the extracted fibers in salt solution and pure water as shown by the $\mathrm{Y}$ axis $\left(\log \left(\mathrm{A} / \mathrm{A}_{0}\right)\right)$. Blue and red squares (with equation and $\mathrm{R}^{2}$ ) show the observed salting out effect in the salt mixtures and the salting out effect calculated assuming additivity. Error bars for the observed values were calculated from 4 replicates at each concentration. Error bars for the calculated $K_{S, m i x}$ values were calculated from standard errors of $K_{S}$ for individual salt according to equation (2). For comparison, the salting out effect in $\mathrm{NaCl}$ and $\left(\mathrm{NH}_{4}\right)_{2} \mathrm{SO}_{4}$ solutions is shown with orange and purple circles, respectively. p-values from analysis of covariance are shown for each compound. 
370 Figure S5 shows results for the 2-ketones using the SHPD method. Unlike the results from the

371 SPME method, there is no consistent trend in the discrepancy of the calculated and measured

$372 K_{S, \text { mix }}$. Except for 2-hexanone, the observed and calculated slopes are not significantly different

373 ( $>0.05)$, indicating additivity. The observed slope for 2-hexanone is much lower than expected

374 from additivity, which might be partially due to experimental uncertainties. In order to explain

375 the different observations of additivity for 2-ketones using the two experimental methods, we

376 compared the measurements of $K_{\mathrm{S}}$ for individual salts in Table S9. For all the salts except for

$377 \mathrm{NH}_{4} \mathrm{NO}_{3}$, the SHPD measurements always have a higher relative standard error $\left(\mathrm{SE} / K_{S}\right.$ in Table

378 S9). This indicates the SPME measurements for the 2-ketones are generally more precise than

379 the SHPD measurements. The fact that the SHPD measurements indicate additivity more

380 frequently than the SPME method is possibly due to the lower precision of the SHPD

381 measurements. This is because more uncertain measurements are more likely to overlap with

382 values calculated by assuming additivity, leading to no significant difference in the statistical

383 analysis.

\section{Discussion of the Additivity of the Salt Effect}

385 From a statistical point of view, we found no significant difference between the values on either 386 side of equations (5) to (7). As a result, for the compounds and salts measured in the present 387 study we cannot reject the hypothesis of an additive salt effect of ions, given the experimental 388 accuracy. However, Figure 2 also indicates considerable differences between different organic 389 solutes in terms of how close to additive the effect of different ions appears to be; some were 390 close to the 1:1 line, other were quite far from that line. For the 2-ketones in salt mixtures, the 391 results were somewhat inconclusive as well: even though the statistical analyses showed non392 additivity for some compounds, the observed salting out effects in a salt mixture were generally 393 quite close to the calculated values using both experimental methods (Figure 3 and Figure S5).

394 It is conceivable that this inconsistency is indicative of real differences between compounds and 395 between salts, as the specific interactions of an ion with an organic compound may vary between 396 ions and compounds. If that is the case, the specific interactions may prevent the extrapolation of 397 the relations found in this study to other compounds and salt solutions. On the other hand, we 398 cannot discount experimental uncertainty as the source of that inconsistency, especially as 399 experimental errors can be compound specific and the investigation of the additivity of the salt 400 effects is particularly sensitive to data uncertainty. The analysis depicted in Figure 3 is based on 
401 data from three $K_{\mathrm{S}}$ measurements, i.e. the $K_{S}$ for $\mathrm{NaCl},\left(\mathrm{NH}_{4}\right)_{2} \mathrm{SO}_{4}$, and the mixture, which all 402 have an error. The analyses depicted in Figure 2 even required measured $K_{S}$ for four different 403 salts. It is noteworthy that panel c in Figure 2 (based on eq. 7) appears to give a clearer indication 404 of additivity than panels a and b (based on eqs. 5 and 6). We believe that this is due to the 405 comparison of larger and therefore relatively less uncertain terms (note that the scales in Figure $4062 \mathrm{a}$ and $2 \mathrm{~b}$ are smaller than in Figure 2c). Clearly, the relative error of the difference between the $407 K_{\mathrm{S}}$ of two salts (Figure $2 \mathrm{a}$ and $2 \mathrm{~b}$ ) is larger than the error of the sum of the $K_{S}$ for two salts 408 (Figure 2c). Equation of type (7) may thus be better suited to test additivity of the salt effect of 409 ions than equations of type (5) and (6).

410 The salt effect is a very complex phenomenon and it is even more complex in salt mixtures. 411 Theoretically, we would expect an additive salt effect in mixtures if the effect of ions is additive 412 for individual salts according to equations (2) and (4). While our experimental data indicate that 413 the salt effect of mixtures may not be entirely additive, the deviation from additivity seems quite 414 small for the compounds and aqueous solutions studied. For most practical applications, it may 415 be justified to assume additivity of the salt effect, as the error introduced by this assumption is 416 likely small relative to the overall uncertainty in the magnitude of the salt effect.

417 More measurements with high quality and precision in salt mixtures for compounds with various 418 structures (or properties such as polarities) are needed in order to unravel the salt effect in 419 mixtures of salts and potential difference between various compounds. We note that for data 420 analysis, especially for testing additivity, $K_{\mathrm{S}}$ measurements need to not only be of high quality, 421 but also of known quality. It is thus very important to report $K_{\mathrm{S}}$ measurement uncertainties, such 422 as standard deviations/errors.

\section{Acknowledgement}

424 We thank Satoshi Endo and Kai-Uwe Goss for help discussions and suggestions. We 425 acknowledge funding from an Ontario Graduate Scholarship and from the Natural Sciences and 426 Engineering Research Council of Canada.

\section{Supporting Information}

428 Additional information on the experimental method used for each compound, information for the 429 salt solutions, data from the literature, solute descriptors, and additional tables and figures 
430 referenced in the text is provided in Supporting Information. This information is available free of

431 charge via the Internet at http://pubs.acs.org/.

\section{References}

433 1. Herrmann, H.; Schaefer, T.; Tilgner, A.; Styler, S. A.; Weller, C.; Teich, M.; Otto, T., 434 Tropospheric aqueous-phase chemistry: kinetics, mechanisms, and its coupling to a changing gas 435 phase. Chemical Reviews 2015, 115, (10), 4259-4334.

436 2. Schwarzenbach, R. P.; Gschwend, P. M.; Imboden, D. M., Environmental Organic 437 Chemistry. 2. ed.; John Wiley \& Sons: Hoboken, 2003.

438 3. Setschenow, J., Über die Konstitution der Salzlösungen auf Grund ihres Verhaltens zu 439 Kohlensäure. Z. Phys. Chem. 1889, 4, 117-125.

$440 \quad 4 . \quad$ Endo, S.; Pfennigsdorff, A.; Goss, K. U., Salting-out effect in aqueous NaCl solutions: 441 trends with size and polarity of solute molecules. Environmental Science \& Technology 2012, 442 46, (3), 1496-1503.

$443 \quad 5 . \quad$ Wang, C.; Lei, Y. D.; Endo, S.; Wania, F., Measuring and modeling the salting-out effect 444 in ammonium sulfate solutions. Environmental Science \&amp; Technology 2014, 48, (22), $445 \quad 13238-13245$.

$446 \quad$ 6. Xie, W. H.; Shiu, W. Y.; Mackay, D., A review of the effect of salts on the solubility of 447 organic compounds in seawater. Marine Environmental Research 1997, 44, (4), 429-444.

$448 \quad 7 . \quad$ Görgényi, M.; Dewulf, J.; Van Langenhove, H.; Heberger, K., Aqueous salting-out effect 449 of inorganic cations and anions on non-electrolytes. Chemosphere 2006, 65, (5), 802-810.

$450 \quad$ 8. $\quad$ Kim, K.; Seo, K.; Lee, J.; Kim, M.-G.; Ha, K.-S.; Kim, C., Investigation and prediction of 451 the salting-out effect of methane in various aqueous electrolyte solutions. Journal of Industrial 452 and Engineering Chemistry 2016, 34, 117-121.

453 9. Sanemasa, I.; Arakawa, S.; Araki, M.; Deguchi, T., The effects of salts on the solubilities 454 of benzene, toluene, ethylbenzene, and propylbenzene in water. Bulletin of the Chemical Society 455 of Japan 1984, 57, (6), 1539-1544.

456 10. Waxman, E. M.; Elm, J.; Kurtén, T.; Mikkelsen, K. V.; Ziemann, P. J.; Volkamer, R., 457 Glyoxal and methylglyoxal setschenow salting constants in sulfate, nitrate, and chloride 458 solutions: measurements and Gibbs energies. Environmental Science \& Technology 2015, 49, 459 (19), 11500-11508.

460 11. Fredenslund, A.; Gmehling, J.; Rasmussen, P., Vapor-Liquid Equilibria Using 461 UNIFAC:A Group-Contribution Method Elsevier Scientific Publishing, New York: 1977.

462 12. Raatikainen, T.; Laaksonen, A., Application of several activity coefficient models to 463 water-organic-electrolyte aerosols of atmospheric interest. Atmospheric Chemistry Physics 2005, $4645,(9), 2475-2495$. 
465 13. Zuend, A.; Marcolli, C.; Luo, B. P.; Peter, T., A thermodynamic model of mixed organic466 inorganic aerosols to predict activity coefficients. Atmospheric Chemistry and Physics 2008, 8, 467 (16), 4559-4593.

468 14. Gordon, J. E.; Thorne, R. L., Salt effects on the activity coefficient of naphthalene in mixed aqueous electrolyte solutions. I. Mixtures of two salts. The Journal of Physical Chemistry $470 \quad 1967,71,(13), 4390-4399$.

471 15. Burant, A.; Lowry, G. V.; Karamalidis, A. K., Measurement of Setschenow constants for 472 six hydrophobic compounds in simulated brines and use in predictive modeling for oil and gas 473 systems. Chemosphere 2016, 144, 2247-2256.

474 16. Poulson, S.; Harrington, R.; Drever, J., The solubility of toluene in aqueous salt solutions. 475 Talanta 1999, 48, (3), 633-641.

476 17. McDevit, W. F.; Long, F. A., The activity coefficient of benzene in aqueous salt solutions. Journal of the American Chemical Society 1952, 74, (7), 1773-1777.

18. Pontolillo, J.; Eganhouse, R. P. The search for reliable aqueous solubility (Sw) and octanol-water partition coefficient (Kow) data for hydrophobic organic compounds: DDT and DDE as a case study; 01-4201; U.S Geological Survey: Reston, Virginia, 2001.

19. US EPA, Estimation Programs Interface Suite ${ }^{\mathrm{TM}}$ for Microsoft ${ }^{\circledR}$ Windows, v 4.11 or insert version used]. United States Environmental Protection Agency, Washington, DC, USA. In 4832012.

20. Endo, S.; Watanabe, N.; Ulrich, N.; Bronner, G.; Goss, K.-U., UFZ-LSER database v 2.1 [Internet], Leipzig, Germany, Helmholtz Centre for Environmental Research-UFZ. [accessed on 29.05.2016].

Available

from http://www.ufz.de/index.php?en=31698\&contentonly=1\&lserd data[mvc]=Public/start. In 2016.

488 21. Randall, M.; Failey, C. F., The activity coefficient of non-electrolytes in aqueous salt solutions from solubility measurements. the salting-out order of the ions. Chemical Reviews 1927, 4, (3), 285-290.

491 22. Kampf, C. J.; Waxman, E. M.; Slowik, J. G.; Dommen, J.; Pfaffenberger, L.; Praplan, A. 492 P.; Prevot, A. S. H.; Baltensperger, U.; Hoffmann, T.; Volkamer, R., Effective Henry's law 493 partitioning and the salting constant of glyoxal in aerosols containing sulfate. Environmental 494 Science \& Technology 2013, 47, (9), 4236-4244.

495 23. Chen, C. C.; Zhu, Y.; Evans, L. B., Phase partitioning of biomolecules: solubilities of amino acids. Biotechnology Progress 1989, 5, (3), 111-118.

497 24. Sada, E.; Kito, S.; Ito, Y., Solubility of toluene in aqueous salt solutions. Journal of 498 Chemical \&amp; Engineering Data 1975, 20, (4), 373-375.

499 25. Almeida, M. B.; Alvarez, A. M.; Demiguel, E. M.; Delhoyo, E. S., Setchenow 500 coefficients for naphthols by distribution method. Canadian Journal of Chemistry-Revue 501 Canadienne De Chimie 1983, 61, (2), 244-248. 
502 26. Sada, E.; Kito, S.; Ito, Y., Solubility of toluene in aqueous salt solutions. Journal of 503 Chemical \& Engineering Data 1975, 20, (4), 373-375.

504 27. Hofmeister, F., Zur Lehre von der Wirkung der Salze. Archiv für experimentelle 505 Pathologie und Pharmakologie 1888, 25, (1), 1-30.

506 28. Kunz, W.; Henle, J.; Ninham, B. W., 'Zur Lehre von der Wirkung der Salze' (about the 507 science of the effect of salts): Franz Hofmeister's historical papers. Current Opinion in Colloid \& 508 Interface Science 2004, 9, (1-2), 19-37.

509 29. Grover, P. K.; Ryall, R. L., Critical appraisal of salting-out and its implications for 510 chemical and biological sciences. Chemical Reviews 2005, 105, (1), 1-10.

$51130 . \quad$ Long, F. A.; McDevit, W. F., Activity coefficients of nonelectrolyte solutes in aqueous 512 salt solutions. Chemical Reviews 1952, 51, (1), 119-169.

513 31. Gross, P. M., The "salting out" of non-electrolytes from aqueous solutions. Chemical 514 Reviews 1933, 13, (1), 91-101.

515 32. Born, M., Volumen und hydratationswärme der ionen. Z. Phys. 1920, 1, 45-48.

516 33. Debye, P.; McAulay, J. Z., Das Elektrische Feld Der Ionen Und Die 517 Neutralsalzwirking (The electric field of ions and the action of neutral salts). Physik Z 1925, 26, $518 \quad 22-29$.

519 34. Álvarez, M. S.; Mateo, A.; Deive, F. J.; Ángeles Sanromán, M.; Rodríguez, A., Influence 520 of the addition of Tween 20 on the phase behaviour of ionic liquids-based aqueous systems. The 521 Journal of Chemical Thermodynamics 2014, 79, 178-183.

$522 \quad 35 . \quad$ Yu, G.; Bayer, A.R.; Galloway, M.M.; Korshavn, K.J.; Fry, C.G.; Keutsch, F.N., 2011, 523 Glyoxal in aqueous ammonium sulfate solutions: Products, kinetics and hydration effects. 524 Environ. Sci. Technol. 2011, 45, 6336-6342. 


\section{Supporting Information for}

\section{The Effect of Sodium Sulfate, Ammonium Chloride, Ammonium Nitrate and Salt Mixtures on Aqueous Phase Partitioning of Organic Compounds}

Chen Wang ${ }^{1}$, Ying Duan Lei ${ }^{1,2}$, Frank Wania ${ }^{1^{*}}$

${ }^{1}$ Department of Chemistry and Department of Physical and Environmental Sciences, University

of Toronto Scarborough, 1265 Military Trail, Toronto, Ontario, Canada MIC 1A4

${ }^{2}$ Department of Chemical Engineering and Applied Chemistry, University of Toronto

Scarborough, 1265 Military Trail, Toronto, Ontario, Canada M1C 1 A4

*To whom correspondence should be addressed: frank.wania@utoronto.ca,+1-416-287-7225

Table of Content

Text $1 \quad$ Shared Headspace Passive Dosing (SHPD) Method …………………............... S2

Figure S 1 Experiment setup of the shared headspace passive dosing method...................... S2

Text 2 Negligible Depletion Solid Phase Micro-extraction (SPME) Method .................. S3

Figure S 2 Experiment setup of the solid phase micro-extraction method............................. S3

Table S 1 Information on the experimental methods ....................................................... S4

Table S $2 \quad$ Concentration and $\mathrm{pH}$ of the salt solutions used during the experiment. ............. S4

Table S $3 \quad$ Solute descriptors for studied compounds from UFZ-LSER database ................. S5

Table S $4 \quad K_{\mathrm{S}}(\mathrm{L} / \mathrm{mol})$ for 2-ketones using SHPD method .................................................. S6

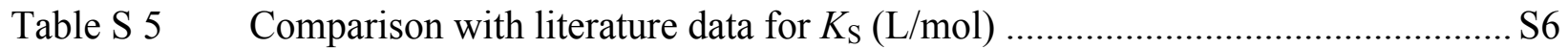

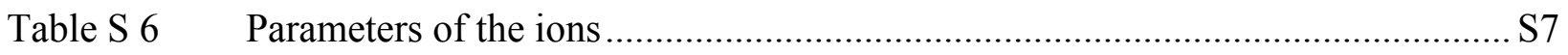

Table $\mathrm{S} 7 \quad$ Literature data $\left(K_{\mathrm{S}}\right.$ in $\left.\mathrm{L} / \mathrm{mol}\right)$ for $\mathrm{pp}$-LFER comparison ..................................... $\mathrm{S} 7$

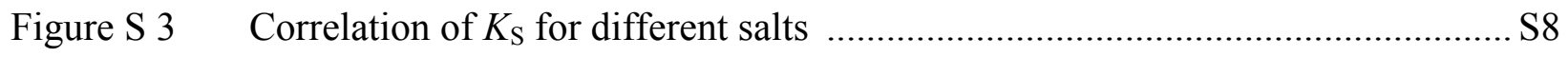

Figure S 4 Dependence of $K_{\mathrm{S}}$ on number of methylene group and McGowan molar volume $(\mathrm{cm} 3 / \mathrm{mol})$ for 2-ketones and alkylbenzenes for different salts ........................... S9

Table S $8 \quad$ Data used in Figure 3 …….......................................................................... S10

Table S 9 Comparison between SHPD and SPME Measurements .................................... S12

Figure 5 Salting out effect in salt mixture (1: 1 mole ratio $\mathrm{NaCl}$ and $\left.\left(\mathrm{NH}_{4}\right)_{2} \mathrm{SO}_{4}\right)$ measured using the SHPD method................................................................................ $\mathrm{S} 13$ 


\section{Text 1 Shared Headspace Passive Dosing (SHPD) Method}

As illustrated in Figure S1, in a closed glass container, a spiked non-volatile organic solvent was used as a donor phase (i.e. $100 \mathrm{~mL}$ olive oil) providing the test compounds to water and salt solutions in small petri dishes ( $25 \mathrm{~mL}$ solution each). The transfer of chemicals from the organic solvent to the aqueous phases takes place via the headspace, which is shared by all individual aqueous phases in the petri dishes in the closed container. At equilibrium, samples of aqueous phase solution were taken through a septum on top of the big glass container. The aqueous solutions were then extracted with solvents and analyzed using GC-MS. The relative difference in the concentrations of the test solutes in the aqueous solutions reflects the degree of salting-out.

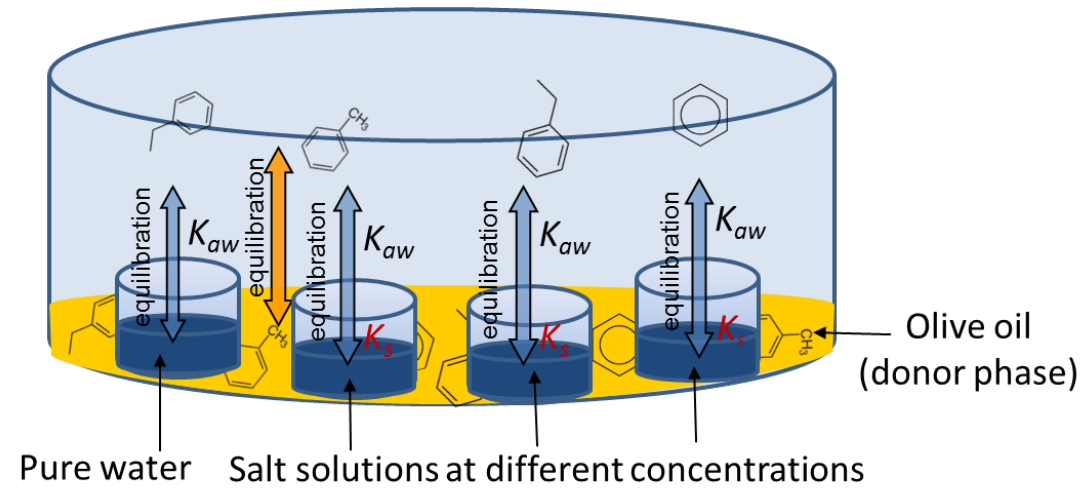

Figure S 1 Experiment setup of the shared headspace passive dosing method. $K_{a w}$ is the partitioning coefficient of the organic solute between the headspace and the water phase. The blue and orange color arrows illustrate the transfer of organic compounds between the headspace and the aqueous solutions and between the headspace and the olive oil, respectively.

The values of $K_{S}$ can be calculated using the following equation based on GC peak areas.

$\log \mathrm{A}_{[\text {salt }]}=-K_{S}[\mathrm{salt}]+\mathrm{c}$

where $\mathrm{A}_{\text {[salt] }}$ is the measured peak area of an organic compound for a given salt concentration [salt], and $K_{S}$ and $\mathrm{c}$ are the slope and intercept, respectively, of the linear regression. The regression analysis was typically performed using at least 12 measured peak areas (four replicates $\times$ at least three salt concentrations as shown in Table S2). The standard error (SE as shown in Table 1 for each compound) of the slope was calculated to indicate the error in the determined $K_{S}$. 


\section{Text 2 Negligible Depletion Solid Phase Micro-extraction (SPME) Method}

In this method (Figure S2), pure water and salt solutions of the same volume receive a constant amount of test compound and a piece of SPME fiber. Organic compounds partition between the aqueous solution and the SPME fiber. At equilibrium, the SPME fibers were then extracted with solvents and analyzed using GC-MS. If the fibers absorb only a negligible amount of compounds and if the headspace volume is small enough, aqueous concentrations remain constant across the solutions with different salt concentrations (i.e. negligible depletion). The relative fiber phase concentrations directly reflect the salting out effects.
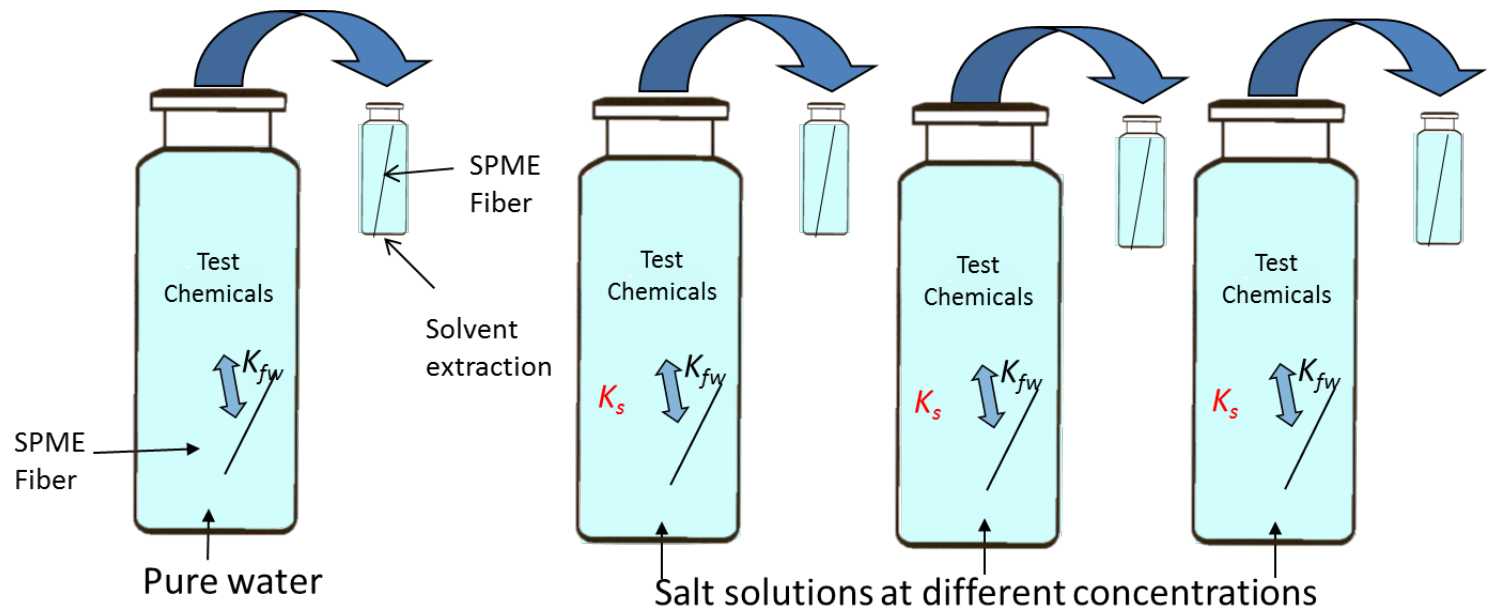

Figure S 2 Experiment setup of the solid phase micro-extraction method. $K_{f w}$ is the partitioning coefficient of the organic solute between the SPME fiber and the water phase. The blue color arrows illustrate the transfer of organic compounds between the aqueous solutions and the SPME fiber.

The values of $K_{S}$ can be calculated using the following equation based on GC peak areas.

$\log \mathrm{A}_{[\text {salt }]}=K_{S}[\mathrm{salt}]+\mathrm{c}$

where $A_{[\text {salt] }}$ is the measured peak area of an organic compound in an SPME fiber that was extracted from a given salt concentration [salt], and $K_{S}$ and $\mathrm{c}$ are the slope and intercept, respectively, of the linear regression. The regression analysis was typically performed using at least 20 measured peak areas (four replicates $\times$ at least five salt concentrations as shown in Table S2). The standard error (SE as shown in Table 1 for each compound) of the slope was calculated to indicate the error in the determined $K_{S}$. 
Table S $1 \quad$ Information on the experimental methods

\begin{tabular}{|c|c|c|c|}
\hline Name & Method $^{\mathrm{a}}$ & Name & Method $^{\mathrm{a}}$ \\
\hline Toluene & SHPD & 1-naphthol & SPME with PA \\
\hline Ethylbenzene & SHPD & 1-hexanol & SPME with PA \\
\hline n-propylbenzene & SHPD & 4-ethyl-3-hexanol & SPME with PA \\
\hline n-butylbenzene & SHPD & 2-butoxyethanol & SPME with PA \\
\hline Pentylbenzene & SHPD & 2-phenylphenol & SPME with PDMS \\
\hline Heptanal & SHPD & 4-nitroaniline & SPME with PA \\
\hline Octanal & SHPD & 4-ntroanisole & SPME with PDMS \\
\hline 1-nitrohexane & SHPD & 2,5-dimethylpyrazine & SPME with PA \\
\hline 1-nitropentane & SHPD & acetanilide & SPME with PA \\
\hline $4: 2 \mathrm{FTOH}$ & SHPD & metalochlor & SPME with PDMS \\
\hline 6:2 FTOH & SHPD & 4-aminobiphenyl & SPME with PDMS \\
\hline 2-hexanone & SHPD \& SPME with PA & atrazine & SPME with PDMS \\
\hline 2-heptanone & SHPD \& SPME with PA & methyl phenyl sulfoxide & SPME with PA \\
\hline 2-octanone & SHPD \& SPME with PA & tri-n-butylphosphate & SPME with PDMS \\
\hline 2-nonanone & SHPD \& SPME with PA & d-n-propylphthalate & SPME with PDMS \\
\hline 2-decanone & SHPD \& SPME with PA & 4-fluorophenol & SPME with PA \\
\hline benzophenone & SPME with PDMS & 4-iodophenol & SPME with PA \\
\hline valerophenone & SPME with PDMS & caffeine & SPME with PA \\
\hline bisphenol a & SPME with PA & carbazole & SPME with PDMS \\
\hline
\end{tabular}

${ }^{a}$ SHPD is the shared headspace passive dosing method, SPME is the solid phase microextraction method using fibres made from either PA (Polyacrylate fibers, $36 \mu \mathrm{m}$ coating thickness, $16.5 \mu \mathrm{L} / \mathrm{m}$ coating volume) or PDMS (Polydimethylsiloxane fibers, $30 \mu \mathrm{m}$ coating thickness, $13.2 \mu \mathrm{L} / \mathrm{m}$ coating volume).

Table $2 \quad$ Concentration and $\mathrm{pH}$ of the salt solutions used during the experiment.

\begin{tabular}{lccc}
\hline & $\begin{array}{c}\text { Concentration } \\
(\mathrm{mol} / \mathrm{L})\end{array}$ & $\mathrm{pH}^{\mathrm{a}}$ & $\mathrm{pH}^{\mathrm{b}}$ \\
\hline & 2.5 & 4.73 & 4.461 \\
$\mathrm{NH}_{4} \mathrm{NO}_{3}$ & 3.75 & 4.52 & 4.351 \\
& 5 & 4.44 & 4.240 \\
\hline & 0.93 & 4.90 & 4.698 \\
$\mathrm{NH}_{4} \mathrm{Cl}$ & 1.87 & 4.74 & 4.640 \\
& 3.74 & 4.52 & 4.381 \\
\hline & 0.18 & 5.89 & 5.752 \\
$\mathrm{Na}_{2} \mathrm{SO}_{4}$ & 0.28 & 6.04 & 5.909 \\
& 0.35 & 6.14 & 5.906 \\
\hline $\mathrm{a}, \mathrm{b}$ & $\mathrm{pH}$ & &
\end{tabular}

\begin{tabular}{cccc}
\hline & $\begin{array}{c}\text { Concentration } \\
(\mathrm{mol} / \mathrm{L})\end{array}$ & $\mathrm{pH}^{\mathrm{a}}$ & $\mathrm{pH}^{\mathrm{b}}$ \\
\hline \multirow{2}{*}{$\left(\mathrm{NH}_{4}\right) \mathrm{SO}_{4}{ }^{\mathrm{c}}$} & 0.38 & 5.34 & 5.160 \\
& 0.76 & 5.30 & 5.158 \\
\hline \multirow{2}{*}{$\mathrm{NaCl}^{\mathrm{d}}$} & 0.86 & 6.34 & 6.067 \\
& 1.72 & 6.72 & 6.537 \\
\hline \multirow{2}{*}{$\mathrm{NaCl} /\left(\mathrm{NH}_{4}\right)_{2} \mathrm{SO}_{4}$} & 0.5 & 5.29 & 5.277 \\
$\mathrm{mixture}$ & 1 & 5.32 & 5.188 \\
$(1: 1 \mathrm{molar}$ ratio $)$ & 2 & 5.25 & 5.157 \\
& 3 & 5.19 & 5.081 \\
\hline
\end{tabular}

${ }^{\mathrm{a}, \mathrm{b}} \mathrm{pH}$ measured with different $\mathrm{pH}$ meters, ${ }^{\mathrm{c}}$ ref. $^{1},{ }^{\mathrm{d}}$ ref. $^{2}$ 
Table S 3 Solute descriptors for studied compounds from UFZ-LSER database ${ }^{3}$

\begin{tabular}{|c|c|c|c|c|c|}
\hline Compound & $\mathrm{E}$ & $\mathrm{S}$ & $\mathrm{A}$ & $\mathrm{B}$ & $\mathrm{V}$ \\
\hline toluene & 0.601 & 0.52 & 0 & 0.14 & 0.8573 \\
\hline ethylbenzene & 0.613 & 0.51 & 0 & 0.15 & 0.9982 \\
\hline propylbenzene & 0.604 & 0.5 & 0 & 0.15 & 1.1391 \\
\hline butylbenzene & 0.6 & 0.51 & 0 & 0.15 & 1.28 \\
\hline pentylbenzene & 0.594 & 0.51 & 0 & 0.15 & 1.4209 \\
\hline heptanal & 0.14 & 0.65 & 0 & 0.45 & 1.1106 \\
\hline octanal & 0.16 & 0.65 & 0 & 0.45 & 1.2515 \\
\hline 1-nitrohexane & 0.203 & 0.95 & 0 & 0.29 & 1.1282 \\
\hline 1-nitropentane & 0.212 & 0.95 & 0 & 0.29 & 0.9873 \\
\hline 4:2 FTOH & -0.67 & 0.2 & 0.55 & 0.25 & 1.352 \\
\hline 6:2 FTOH & -1.04 & 0.2 & 0.55 & 0.25 & 1.7846 \\
\hline 2-hexanone & 0.136 & 0.68 & 0 & 0.51 & 0.9697 \\
\hline 2-heptanone & 0.123 & 0.68 & 0 & 0.51 & 1.1106 \\
\hline 2-octanone & 0.108 & 0.68 & 0 & 0.51 & 1.2515 \\
\hline 2-nonanone & 0.119 & 0.68 & 0 & 0.51 & 1.3924 \\
\hline 2-decanone & 0.108 & 0.68 & 0 & 0.51 & 1.5333 \\
\hline benzophenone & 1.447 & 1.5 & 0 & 0.5 & 1.4808 \\
\hline valerophenone & 0.795 & 0.95 & 0 & 0.5 & 1.4366 \\
\hline bisphenol a & 1.607 & 1.56 & 0.99 & 0.91 & 1.8643 \\
\hline 1-naphthol & 1.52 & 1.1 & 0.66 & 0.34 & 1.1441 \\
\hline 1-hexanol & 0.21 & 0.42 & 0.37 & 0.48 & 1.0127 \\
\hline 4-ethyl-3-hexanol & 0.17 & 0.36 & 0.33 & 0.57 & 1.2945 \\
\hline 2-butoxyethanol & 0.201 & 0.53 & 0.26 & 0.83 & 1.0714 \\
\hline 2-phenylphenol & 1.55 & 1.4 & 0.56 & 0.49 & 1.3829 \\
\hline 4-nitroaniline & 1.22 & 1.92 & 0.46 & 0.35 & 0.9904 \\
\hline 4-nitroanisole & 0.97 & 1.29 & 0 & 0.4 & 1.0902 \\
\hline 2,5-dimethylpyrazine & 0.626 & 0.9 & 0 & 0.69 & 0.916 \\
\hline acetanilide & 0.9 & 1.37 & 0.48 & 0.67 & 1.1137 \\
\hline metolachlor & 1.15 & 1.01 & 0.07 & 1.38 & 2.2811 \\
\hline 4-aminobiphenyl & 1.565 & 1.48 & 0.26 & 0.48 & 1.424 \\
\hline atrazine & 1.22 & 1.29 & 0.17 & 1.01 & 1.6196 \\
\hline methylphenylsulfoxide & 1.104 & 1.8 & 0 & 0.91 & 1.08 \\
\hline tri-n-butylphosphate & -0.1 & 0.9 & 0 & 1.21 & 2.239 \\
\hline di-n-propylphthalate & 0.713337 & 1.4 & 0 & 0.88 & 1.9924 \\
\hline 4-fluorophenol & 0.67 & 0.97 & 0.63 & 0.23 & 0.8128 \\
\hline 4-iodophenol & 1.38 & 1.22 & 0.68 & 0.2 & 1.0333 \\
\hline caffeine & 1.5 & 1.82 & 0.08 & 1.25 & 1.3632 \\
\hline carbazole & 1.787 & 1.42 & 0.47 & 0.26 & 1.3154 \\
\hline o-xylene & 0.663 & 0.56 & 0 & 0.16 & 0.9982 \\
\hline
\end{tabular}


Table S 3 (continued)

\begin{tabular}{lccccc}
\hline Compound & $\mathrm{E}$ & $\mathrm{S}$ & $\mathrm{A}$ & $\mathrm{B}$ & $\mathrm{V}$ \\
\hline m-xylene & 0.623 & 0.52 & 0 & 0.16 & 0.9982 \\
p-xylene & 0.61 & 0.52 & 0 & 0.16 & 0.9982 \\
naphthalene & 1.34 & 0.92 & 0 & 0.2 & 1.0854 \\
chloroform & 0.425 & 0.49 & 0.15 & 0.02 & 0.6167 \\
benzene & 0.61 & 0.52 & 0 & 0.14 & 0.7164 \\
chlorobenzene & 0.718 & 0.65 & 0 & 0.07 & 0.8388 \\
anisole & 0.708 & 0.75 & 0 & 0.29 & 0.916 \\
n-hexane & 0 & 0 & 0 & 0 & 0.954 \\
phenanthrene & 2.06 & 1.29 & 0 & 0.29 & 1.454 \\
chlorobenzene & 0.72 & 0.65 & 0 & 0.07 & 0.839 \\
1,4-dichlorobenzene & 0.83 & 0.75 & 0 & 0.02 & 0.961 \\
\hline
\end{tabular}

Table S $4 \quad K_{S}(\mathrm{~L} / \mathrm{mol})$ for 2-ketones using SHPD method

\begin{tabular}{l|cccc|cccc|cccc}
\hline & \multicolumn{4}{|c|}{$\mathrm{NH}_{4} \mathrm{NO}_{3}$} & \multicolumn{4}{c|}{$\mathrm{NH}_{4} \mathrm{Cl}$} & \multicolumn{4}{c}{$\mathrm{Na}_{2} \mathrm{SO}_{4}$} \\
& $K_{S}$ & $\mathrm{SE}$ & $\mathrm{R}^{2}$ & $\Delta K_{S}^{\mathrm{a}}$ & $K_{S}$ & $\mathrm{SE}$ & $\mathrm{R}^{2}$ & $\Delta K_{S}^{\mathrm{a}}$ & $K_{S}$ & $\mathrm{SE}$ & $\mathrm{R}^{2}$ & $\Delta K_{S}^{\mathrm{a}}$ \\
\hline 2-hexanone & 0.045 & 0.003 & 0.97 & 0.011 & 0.078 & 0.008 & 0.93 & 0.053 & 0.567 & 0.040 & 0.95 & 0.143 \\
2-heptanone & 0.065 & 0.003 & 0.99 & 0.005 & 0.125 & 0.007 & 0.97 & 0.032 & 0.887 & 0.050 & 0.97 & 0.075 \\
2-octanone & 0.066 & 0.004 & 0.98 & 0.004 & 0.148 & 0.005 & 0.99 & 0.045 & 0.987 & 0.066 & 0.96 & 0.003 \\
2-nonanone & 0.083 & 0.006 & 0.97 & 0.000 & 0.180 & 0.008 & 0.98 & 0.013 & 1.197 & 0.084 & 0.95 & 0.122 \\
2-decanone & 0.093 & 0.011 & 0.91 & 0.024 & 0.200 & 0.023 & 0.89 & 0.012 & 1.378 & 0.157 & 0.92 & 0.001 \\
\hline
\end{tabular}

${ }^{\mathrm{a}} \Delta K_{S}$ is the absolute difference of $K_{S}$ between SPME and SHPD methods.

Table S 5 Comparison with literature data for $K_{S}(\mathrm{~L} / \mathrm{mol})$

\begin{tabular}{|c|c|c|c|c|c|c|c|c|}
\hline & \multicolumn{2}{|c|}{$\mathrm{NH}_{4} \mathrm{Cl}$} & \multicolumn{2}{|c|}{$\mathrm{Na}_{2} \mathrm{SO}_{4}$} & \multicolumn{2}{|c|}{$\left(\mathrm{NH}_{4}\right)_{2} \mathrm{SO}_{4}$} & \multicolumn{2}{|c|}{$\mathrm{NaCl}$} \\
\hline & literature & this study & literature & this study & literature & Wang et al. ${ }^{1}$ & Literature & Endo et al. ${ }^{2}$ \\
\hline 1-naphthol & $0.101 \pm 0.005^{\mathrm{a}}$ & $0.03 \pm 0.007$ & NA & - & NA & - & $0.209 \pm 0.008^{\mathrm{a}}$ & $0.182 \pm 0.009$ \\
\hline toluene & $0.055^{\mathrm{b}}$ & $0.112 \pm 0.05$ & $0.65^{\mathrm{b}}$ & $0.59 \pm 0.04$ & $0.415^{\mathrm{b}}$ & $0.465 \pm 0.016$ & $0.267^{\mathrm{b}}$ & $0.221 \pm 0.024$ \\
\hline toluene & $0.136^{\mathrm{c}}$ & $0.112 \pm 0.05$ & $0.651^{\mathrm{c}}$ & $0.59 \pm 0.04$ & $0.428^{\mathrm{c}}$ & $0.465 \pm 0.016$ & $0.225^{\mathrm{c}}$ & $0.221 \pm 0.024$ \\
\hline toluene & NA & - & $0.684^{\mathrm{d}}$ & $0.59 \pm 0.04$ & NA & - & $0.242^{\mathrm{d}}$ & $0.221 \pm 0.024$ \\
\hline ethylbenzene & NA & - & $0.693^{\mathrm{d}}$ & $0.66 \pm 0.062$ & NA & - & $0.28^{\mathrm{d}}$ & $0.238 \pm 0.025$ \\
\hline propylbenzene & NA & - & $0.748^{\mathrm{d}}$ & $0.848 \pm 0.06$ & NA & - & $0.281^{\mathrm{d}}$ & $0.262 \pm 0.025$ \\
\hline
\end{tabular}

${ }^{\mathrm{a}}$ Almeida et al. ${ }^{4 \mathrm{~b}}$ Sada et al. ${ }^{5 \mathrm{c}}$ Xie et al. ${ }^{6}{ }^{\mathrm{d}}$ Sanemasa et al. ${ }^{7}$ 
Table S 6 Parameters of the ions

\begin{tabular}{lccccc}
\hline ion & radius ${ }^{\mathrm{a}}(\mathrm{r}, \AA)$ & charge $(\mathrm{z})$ & $\mathrm{z}^{2} / \mathrm{r}$ & $\Delta \mathrm{G}_{\mathrm{hyd}}(\mathrm{kJ} / \mathrm{mol})^{\mathrm{b}}$ & $\Delta \mathrm{G}_{\mathrm{hyd}}(\mathrm{kJ} / \mathrm{mol})^{\mathrm{c}}$ \\
\hline $\mathrm{SO}_{4}{ }^{2-}$ & 2.58 & 2 & 1.55 & $\mathrm{NA}$ & -1080 \\
$\mathrm{Cl}^{-}$ & 1.84 & 1 & 0.54 & -378 & -340 \\
$\mathrm{NO}_{3}{ }^{-}$ & 1.79 & 1 & 0.56 & -314 & -300 \\
$\mathrm{NH}_{4}^{+}$ & 1.37 & 1 & 0.73 & -307 & $\mathrm{NA}$. \\
$\mathrm{Na}^{+}$ & 1.02 & 1 & 0.98 & -406 & -365 \\
\hline
\end{tabular}

${ }^{\text {a }}$ data from http://www.wiredchemist.com/chemistry/data/atomic-and-ionic-radii

${ }^{b}$ absolute enthalpies of hydration of gaseous ions from http://www.wiredchemist.com/chemistry/data/enthalpieshydration

${ }^{\mathrm{c}}$ predicted hydration energies from ref. ${ }^{8}$

Table S 7 Literature data $\left(K_{S}\right.$ in $\left.\mathrm{L} / \mathrm{mol}\right)$ for pp-LFER comparison in Figure 2 and additivity testing in Figure 3

\begin{tabular}{|c|c|c|c|c|c|c|}
\hline & $\mathrm{NH}_{4} \mathrm{NO}_{3}$ & $\mathrm{NH}_{4} \mathrm{Cl}$ & $\mathrm{Na}_{2} \mathrm{SO}_{4}$ & $\left(\mathrm{NH}_{4}\right)_{2} \mathrm{SO}_{4}$ & $\mathrm{NaCl}$ & References \\
\hline chloroform & $0.0239 \pm 0.034$ & $0.0717 \pm 0.022$ & $0.502 \pm 0.014$ & $0.309 \pm 0.031$ & $0.208 \pm 0.037$ & ref. $^{9}$ \\
\hline benzene & $0.0746 \pm 0.03$ & $0.124 \pm 0.021$ & $0.519 \pm 0.016$ & $0.366 \pm 0.035$ & $0.248 \pm 0.060$ & ref. ${ }^{9}$ \\
\hline chlorobenzene & $0.0342 \pm 0.031$ & $0.126 \pm 0.026$ & $0.565 \pm 0.02$ & $0.374 \pm 0.042$ & $0.257 \pm 0.052$ & ref. ${ }^{9}$ \\
\hline anisole & $0.0123 \pm 0.031$ & $0.118 \pm 0.023$ & $0.635 \pm 0.016$ & $0.415 \pm 0.021$ & $0.225 \pm 0.033$ & ref. ${ }^{9}$ \\
\hline benzene & NA. & 0.103 & 0.548 & 0.405 & 0.195 & ref. $^{6}$ \\
\hline toluene & NA. & 0.136 & 0.651 & 0.428 & 0.225 & ref. $^{6}$ \\
\hline o-xylene & NA. & 0.102 & 0.641 & 0.496 & 0.227 & ref. $^{6}$ \\
\hline m-xylene & NA. & 0.153 & 0.691 & 0.551 & 0.248 & ref. $^{6}$ \\
\hline p-xylene & NA. & 0.099 & 0.656 & 0.499 & 0.251 & ref. $^{6}$ \\
\hline naphthalene & NA. & 0.071 & 0.695 & 0.476 & 0.260 & ref. $^{6}$ \\
\hline n-hexane & NA. & 0.181 & 0.788 & NA. & NA. & ref. $^{6}$ \\
\hline biphenyl & NA. & NA. & 0.846 & NA. & NA. & ref. $^{6}$ \\
\hline phenanthrene & NA. & NA. & 0.784 & NA. & NA. & ref. $^{6}$ \\
\hline chlorobenzene & NA. & NA. & 0.580 & NA. & NA. & ref. $^{6}$ \\
\hline p-dichlorobenzene & NA. & NA. & 0.586 & NA. & NA. & ref. $^{6}$ \\
\hline
\end{tabular}



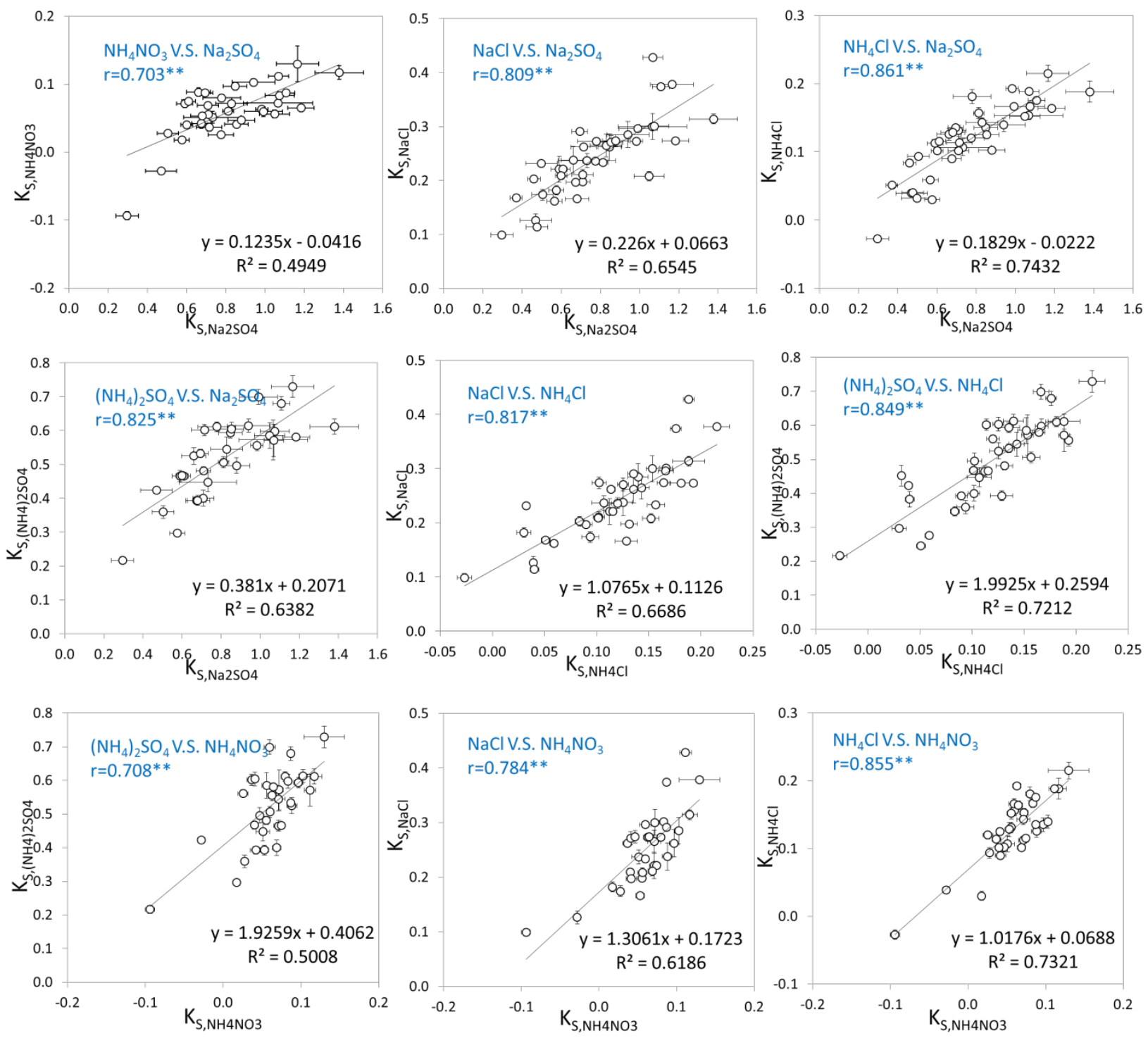

Figure S 3 Correlation of $K_{S}$ for different salts ( $\mathrm{N}=33$ for $\mathrm{NH}_{4} \mathrm{NO}_{3}$ and $\mathrm{N}=38$ for other salts). The error bars show the standard error in each measurement. The correlation between the $K_{S}$ for $\mathrm{NaCl}$ and $\left(\mathrm{NH}_{4}\right)_{2} \mathrm{SO}_{4}$ has been previously described ${ }^{5}$ and is not shown here. 

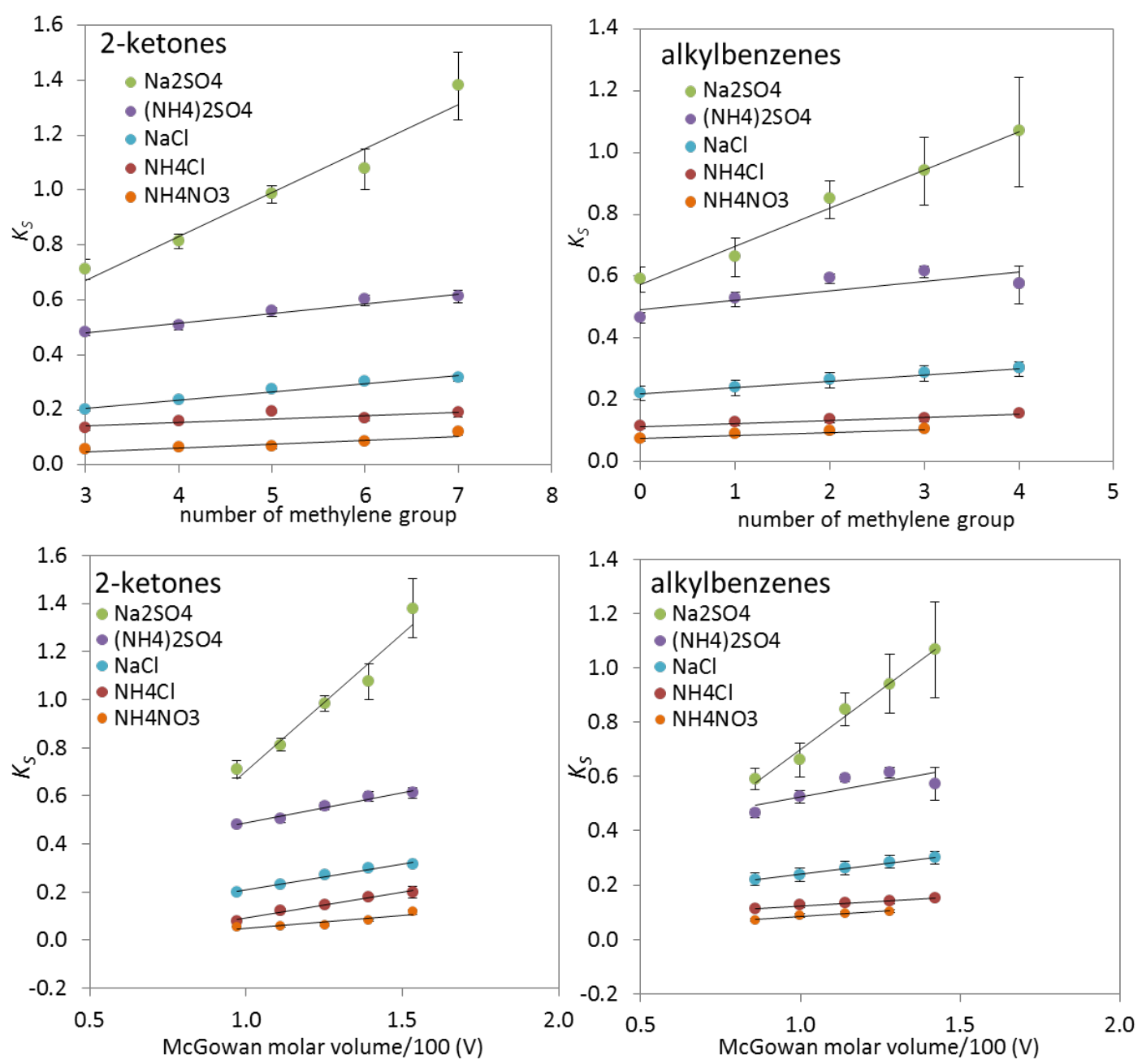

\begin{tabular}{llll}
\hline & \multicolumn{2}{c}{ 2-ketones } & Alkylbenzenes \\
\hline \multirow{4}{*}{$\begin{array}{lll}\text { number of } \\
\text { methylene }\end{array}$} & $\mathrm{Na}_{2} \mathrm{SO}_{4}$ & $\mathrm{Y}=(0.160 \pm 0.020) \mathrm{X}+(0.192 \pm 0.105) \mathrm{R}^{2}=0.954$ & $\mathrm{Y}=(0.123 \pm 0.009) \mathrm{X}+(0.574 \pm 0.022) \mathrm{R}^{2}=0.985$ \\
group & $\mathrm{NHCl}$ & $\mathrm{Y}=(0.030 \pm 0.003) \mathrm{X}+(0.114 \pm 0.015) \mathrm{R}^{2}=0.971$ & $\mathrm{Y}=(0.021 \pm 0.001) \mathrm{X}+(0.220 \pm 0.002) \mathrm{R}^{2}=0.994$ \\
& $\mathrm{NH}_{4} \mathrm{Cl}$ & $\mathrm{Y}=(0.012 \pm 0.006) \mathrm{X}+(0.105 \pm 0.029) \mathrm{R}^{2}=0.615$ & $\mathrm{Y}=(0.010 \pm 0.001) \mathrm{X}+(0.114 \pm 0.002) \mathrm{R}^{2}=0.978$ \\
& $\mathrm{NH}_{4} \mathrm{NO}_{3}{ }^{a}$ & $\mathrm{Y}=(0.015 \pm 0.004) \mathrm{X}+(0.003 \pm 0.020) \mathrm{R}^{2}=0.830$ & $\mathrm{Y}=(0.010 \pm 0.002) \mathrm{X}+(0.074 \pm 0.003) \mathrm{R}^{2}=0.943$ \\
\hline \multirow{3}{*}{$\begin{array}{l}\text { McGowan } \\
\text { molar }\end{array}$} & $\mathrm{Na}_{2} \mathrm{SO}_{4}$ & $\mathrm{Y}=(1.136 \pm 0.144) \mathrm{X}+(-0.430 \pm 0.182) \mathrm{R}^{2}=0.954$ & $\mathrm{Y}=(0.875 \pm 0.063) \mathrm{X}+(-0.176 \pm 0.073) \mathrm{R}^{2}=0.985$ \\
volume/100 & $\left(\mathrm{NH}_{4}\right)_{2} \mathrm{SO}_{4}$ & $\mathrm{Y}=(0.251 \pm 0.024) \mathrm{X}+(0.236 \pm 0.030) \mathrm{R}^{2}=0.973$ & $\mathrm{Y}=(0.214 \pm 0.092) \mathrm{X}+(0.310 \pm 0.106) \mathrm{R}^{2}=0.644$ \\
& $\mathrm{NaCl}^{2}$ & $\mathrm{Y}=(0.213 \pm 0.021) \mathrm{X}+(-0.003 \pm 0.027) \mathrm{R}^{2}=0.979$ & $\mathrm{Y}=(0.145 \pm 0.006) \mathrm{X}+(0.095 \pm 0.007) \mathrm{R}^{2}=0.994$ \\
& $\mathrm{NH}_{4} \mathrm{Cl}^{2}$ & $\mathrm{Y}=(0.212 \pm 0.018) \mathrm{X}+(-0.119 \pm 0.023) \mathrm{R}^{2}=0.954$ & $\mathrm{Y}=(0.068 \pm 0.006) \mathrm{X}+(0.056 \pm 0.007) \mathrm{R}^{2}=0.978$ \\
& $\mathrm{NH}_{4} \mathrm{NO}_{3}{ }^{a}$ & $\mathrm{Y}=(0.104 \pm 0.027) \mathrm{X}+(-0.054 \pm 0.034) \mathrm{R}^{2}=0.830$ & $\mathrm{Y}=(0.0732 \pm 0.013) \mathrm{X}+(0.012 \pm 0.014) \mathrm{R}^{2}=0.943$ \\
\hline
\end{tabular}

${ }^{a}$ Data for pentylbenzene in $\mathrm{NH}_{4} \mathrm{NO}_{3}$ were excluded due to quality.

Figure S 4 Dependence of $K_{S}$ on number of methylene group and McGowan molar volume $\left(\mathrm{cm}^{3} / \mathrm{mol}\right)$ for 2-ketones and alkylbenzenes for different salts 
Table S 8 Data used in Figure 3

\begin{tabular}{|c|c|c|c|c|c|c|c|c|c|c|c|c|}
\hline & \multicolumn{2}{|c|}{$\mathrm{NaCl}-\mathrm{NH}_{4} \mathrm{Cl}$} & \multicolumn{2}{|c|}{$1 / 2\left(\mathrm{Na}_{2} \mathrm{SO}_{4}-\left(\mathrm{NH}_{4}\right)_{2} \mathrm{SO}_{4}\right)$} & \multicolumn{2}{|c|}{$\mathrm{Na}_{2} \mathrm{SO}_{4}-2 \mathrm{NaCl}$} & \multicolumn{2}{|c|}{$\left(\mathrm{NH}_{4}\right)_{2} \mathrm{SO}_{4}-2 \mathrm{NH}_{4} \mathrm{Cl}$} & \multicolumn{2}{|c|}{$\mathrm{Na}_{2} \mathrm{SO}_{4}+2 * \mathrm{NH}_{4} \mathrm{Cl}$} & \multicolumn{2}{|c|}{$2 * \mathrm{NaCl}+\left(\mathrm{NH}_{4}\right)_{2} \mathrm{SO}_{4}$} \\
\hline & $K_{S}$ & SE & $K_{S}$ & SE & $K_{S}$ & SE & $K_{S}$ & SE & $K_{S}$ & SE & $K_{S}$ & SE \\
\hline Toluene & 0.109 & 0.025 & 0.062 & 0.022 & 0.148 & 0.063 & 0.240 & 0.020 & 0.810 & 0.040 & 0.910 & 0.050 \\
\hline Ethylbenzene & 0.112 & 0.026 & 0.068 & 0.033 & 0.184 & 0.080 & 0.274 & 0.030 & 0.910 & 0.060 & 1.000 & 0.060 \\
\hline propylbenzene & 0.127 & 0.027 & 0.127 & 0.031 & 0.324 & 0.078 & 0.323 & 0.026 & 1.120 & 0.060 & 1.120 & 0.050 \\
\hline Butylbenzene & 0.145 & 0.026 & 0.163 & 0.055 & 0.370 & 0.119 & 0.334 & 0.028 & 1.220 & 0.110 & 1.180 & 0.050 \\
\hline pentylbenzene & 0.147 & 0.025 & 0.247 & 0.093 & 0.467 & 0.182 & 0.265 & 0.061 & 1.370 & 0.180 & 1.170 & 0.080 \\
\hline heptanal & 0.130 & 0.018 & 0.142 & 0.075 & 0.258 & 0.149 & 0.234 & 0.037 & 0.950 & 0.150 & 0.920 & 0.040 \\
\hline octanal & 0.122 & 0.022 & 0.142 & 0.044 & 0.299 & 0.092 & 0.259 & 0.038 & 1.110 & 0.080 & 1.080 & 0.050 \\
\hline 1-nitrohexane & 0.116 & 0.012 & 0.107 & 0.033 & 0.303 & 0.069 & 0.321 & 0.017 & 1.010 & 0.070 & 1.030 & 0.020 \\
\hline 1-nitropentane & 0.119 & 0.010 & 0.056 & 0.018 & 0.053 & 0.037 & 0.180 & 0.016 & 0.630 & 0.030 & 0.750 & 0.020 \\
\hline 4:2 FTOH & 0.092 & 0.012 & 0.084 & 0.049 & 0.232 & 0.097 & 0.249 & 0.025 & 1.140 & 0.100 & 1.160 & 0.020 \\
\hline $6: 2 \mathrm{FTOH}$ & 0.163 & 0.013 & 0.218 & 0.057 & 0.410 & 0.109 & 0.299 & 0.041 & 1.600 & 0.110 & 1.490 & 0.030 \\
\hline 2-hexanone & 0.067 & 0.009 & 0.114 & 0.020 & 0.314 & 0.039 & 0.219 & 0.020 & 0.970 & 0.040 & 0.880 & 0.010 \\
\hline 2-heptanone & 0.076 & 0.009 & 0.153 & 0.016 & 0.346 & 0.028 & 0.193 & 0.023 & 1.130 & 0.030 & 0.970 & 0.020 \\
\hline 2-octanone & 0.080 & 0.005 & 0.214 & 0.018 & 0.437 & 0.032 & 0.171 & 0.018 & 1.370 & 0.030 & 1.100 & 0.020 \\
\hline 2-nonanone & 0.134 & 0.007 & 0.238 & 0.039 & 0.473 & 0.075 & 0.265 & 0.024 & 1.410 & 0.080 & 1.200 & 0.020 \\
\hline 2-decanone & 0.126 & 0.018 & 0.384 & 0.062 & 0.751 & 0.124 & 0.235 & 0.038 & 1.760 & 0.130 & 1.240 & 0.030 \\
\hline benzophenone & 0.148 & 0.006 & 0.056 & 0.034 & 0.191 & 0.066 & 0.375 & 0.019 & 0.940 & 0.070 & 1.130 & 0.020 \\
\hline valerophenone & 0.146 & 0.013 & 0.125 & 0.032 & 0.312 & 0.065 & 0.354 & 0.023 & 1.100 & 0.060 & 1.150 & 0.030 \\
\hline bisphenol a & 0.080 & 0.013 & 0.073 & 0.029 & 0.156 & 0.058 & 0.172 & 0.025 & 0.690 & 0.060 & 0.710 & 0.030 \\
\hline 1-naphthol & 0.152 & 0.011 & 0.139 & 0.019 & 0.212 & 0.042 & 0.236 & 0.015 & 0.640 & 0.040 & 0.660 & 0.020 \\
\hline 1-hexanol & 0.106 & 0.005 & 0.072 & 0.018 & 0.168 & 0.036 & 0.235 & 0.008 & 0.840 & 0.040 & 0.910 & 0.010 \\
\hline 4-ethyl-3-hexanol & 0.156 & 0.007 & 0.081 & 0.021 & 0.113 & 0.040 & 0.262 & 0.016 & 0.970 & 0.040 & 1.110 & 0.010 \\
\hline 2-butoxyethanol & 0.109 & 0.011 & 0.154 & 0.029 & 0.287 & 0.057 & 0.196 & 0.025 & 0.910 & 0.050 & 0.820 & 0.030 \\
\hline 2-phenylphenol & 0.172 & 0.013 & 0.191 & 0.036 & 0.331 & 0.071 & 0.292 & 0.027 & 1.080 & 0.070 & 1.040 & 0.030 \\
\hline
\end{tabular}


Table S 8 (continued)

\begin{tabular}{|c|c|c|c|c|c|c|c|c|c|c|c|c|}
\hline & \multicolumn{2}{|c|}{$\mathrm{NaCl}-\mathrm{NH}_{4} \mathrm{Cl}$} & \multicolumn{2}{|c|}{$1 / 2\left(\mathrm{Na}_{2} \mathrm{SO}_{4}-\left(\mathrm{NH}_{4}\right)_{2} \mathrm{SO}_{4}\right)$} & \multicolumn{2}{|c|}{$\mathrm{Na}_{2} \mathrm{SO}_{4}-2 \mathrm{NaCl}$} & \multicolumn{2}{|c|}{$\left(\mathrm{NH}_{4}\right)_{2} \mathrm{SO}_{4}-2 \mathrm{NH}_{4} \mathrm{Cl}$} & \multicolumn{2}{|c|}{$\mathrm{Na}_{2} \mathrm{SO}_{4}+2 * \mathrm{NH}_{4} \mathrm{Cl}$} & \multicolumn{2}{|c|}{$2 * \mathrm{NaCl}+\left(\mathrm{NH}_{4}\right)_{2} \mathrm{SO}_{4}$} \\
\hline & $K_{S}$ & SE & $K_{S}$ & SE & $K_{S}$ & SE & $K_{S}$ & SE & $K_{S}$ & $\mathrm{SE}$ & $K_{S}$ & SE \\
\hline 4-nitroaniline & 0.126 & 0.010 & 0.040 & 0.029 & 0.098 & 0.058 & 0.270 & 0.018 & 0.240 & 0.060 & 0.410 & 0.020 \\
\hline 4-ntroanisole & 0.087 & 0.012 & 0.023 & 0.040 & 0.217 & 0.084 & 0.345 & 0.010 & 0.550 & 0.080 & 0.680 & 0.030 \\
\hline 2,5-dimethylpyrazine & 0.107 & 0.008 & 0.066 & 0.016 & 0.182 & 0.034 & 0.264 & 0.014 & 0.800 & 0.030 & 0.890 & 0.020 \\
\hline acetanilide & 0.107 & 0.007 & 0.141 & 0.025 & 0.280 & 0.050 & 0.213 & 0.016 & 0.850 & 0.050 & 0.790 & 0.020 \\
\hline metalochlor & 0.130 & 0.009 & 0.146 & 0.050 & 0.400 & 0.098 & 0.366 & 0.026 & 1.320 & 0.100 & 1.290 & 0.020 \\
\hline 4-aminobiphenyl & 0.056 & 0.012 & 0.232 & 0.043 & 0.633 & 0.079 & 0.281 & 0.041 & 1.350 & 0.080 & 1.000 & 0.040 \\
\hline atrazine & 0.110 & 0.008 & 0.302 & 0.034 & 0.636 & 0.068 & 0.252 & 0.015 & 1.510 & 0.070 & 1.130 & 0.010 \\
\hline methyl phenyl sulfoxide & 0.038 & 0.012 & 0.144 & 0.031 & 0.349 & 0.062 & 0.136 & 0.026 & 0.940 & 0.060 & 0.730 & 0.020 \\
\hline tri-n-butylphosphate & 0.240 & 0.008 & 0.249 & 0.035 & 0.213 & 0.052 & 0.194 & 0.049 & 1.450 & 0.050 & 1.430 & 0.050 \\
\hline d-n-propylphthalate & 0.198 & 0.007 & 0.214 & 0.024 & 0.360 & 0.045 & 0.328 & 0.023 & 1.460 & 0.040 & 1.430 & 0.020 \\
\hline 4-fluorophenol & 0.117 & 0.006 & 0.062 & 0.016 & 0.033 & 0.032 & 0.143 & 0.012 & 0.470 & 0.030 & 0.580 & 0.010 \\
\hline 4-iodophenol & 0.103 & 0.005 & 0.145 & 0.020 & 0.242 & 0.039 & 0.159 & 0.009 & 0.680 & 0.040 & 0.600 & 0.010 \\
\hline caffeine & 0.074 & 0.008 & 0.047 & 0.030 & 0.248 & 0.057 & 0.302 & 0.025 & 0.560 & 0.060 & 0.610 & 0.030 \\
\hline carbazole & 0.200 & 0.007 & 0.023 & 0.043 & 0.035 & 0.081 & 0.388 & 0.032 & 0.560 & 0.080 & 0.920 & 0.030 \\
\hline chloroform $^{\mathrm{a}}$ & 0.136 & 0.043 & 0.097 & 0.017 & 0.086 & 0.075 & 0.166 & 0.054 & 0.645 & 0.046 & 0.725 & 0.080 \\
\hline benzene $^{\mathrm{a}}$ & 0.124 & 0.064 & 0.077 & 0.019 & 0.023 & 0.121 & 0.118 & 0.055 & 0.770 & 0.040 & 0.860 & 0.130 \\
\hline chlorobenzene $^{\mathrm{a}}$ & 0.131 & 0.058 & 0.096 & 0.023 & 0.051 & 0.106 & 0.122 & 0.067 & 0.820 & 0.060 & 0.890 & 0.110 \\
\hline anisole $^{\mathrm{a}}$ & 0.107 & 0.040 & 0.110 & 0.013 & 0.185 & 0.068 & 0.179 & 0.051 & 0.870 & 0.050 & 0.870 & 0.070 \\
\hline benzene $^{b}$ & 0.092 & NA & 0.072 & NA & 0.158 & NA & 0.199 & NA & 0.754 & NA & 0.795 & NA \\
\hline toluene $^{\mathrm{b}}$ & 0.089 & NA & 0.112 & NA & 0.201 & NA & 0.156 & NA & 0.923 & NA & 0.878 & NA \\
\hline o-xylene ${ }^{b}$ & 0.125 & NA & 0.073 & NA & 0.187 & NA & 0.292 & NA & 0.845 & NA & 0.950 & NA \\
\hline m-xylene ${ }^{b}$ & 0.095 & NA & 0.070 & NA & 0.195 & NA & 0.245 & NA & 0.997 & NA & 1.047 & NA \\
\hline p-xylene ${ }^{b}$ & 0.152 & NA & 0.079 & NA & 0.154 & NA & 0.301 & NA & 0.854 & NA & 1.001 & NA \\
\hline naphthaleneb & 0.189 & NA & 0.110 & NA & 0.175 & NA & 0.334 & NA & 0.837 & NA & 0.996 & NA \\
\hline
\end{tabular}

${ }^{\mathrm{a}}$ Data from ref. ${ }^{9}$ b Data from ref. ${ }^{6}$ 
Table S 9 Comparison between SHPD and SPME Measurements

\begin{tabular}{|c|c|c|c|c|c|c|c|c|c|c|c|}
\hline & & \multicolumn{5}{|c|}{ SHPD } & \multicolumn{5}{|c|}{ SPME } \\
\hline & & 2-hexanone & 2-heptanone & 2-octanone & 2-nonanone & 2-decanone & 2-hexanone & 2-heptanone & 2-octanone & 2-nonanone & 2-decanone \\
\hline \multirow{4}{*}{$\mathrm{NH}_{4} \mathrm{NO}_{3}$} & $K_{S}$ & 0.045 & 0.065 & 0.066 & 0.083 & 0.093 & 0.056 & 0.060 & 0.063 & 0.083 & 0.117 \\
\hline & $\mathrm{SE}$ & 0.003 & 0.003 & 0.004 & 0.006 & 0.011 & 0.003 & 0.004 & 0.005 & 0.005 & 0.010 \\
\hline & $\mathrm{R}^{2}$ & 0.975 & 0.988 & 0.981 & 0.965 & 0.907 & 0.977 & 0.970 & 0.950 & 0.968 & 0.927 \\
\hline & $\mathrm{SE} / K_{S}$ & $6 \%$ & $4 \%$ & $5 \%$ & $7 \%$ & $12 \%$ & $6 \%$ & $7 \%$ & $9 \%$ & $6 \%$ & $8 \%$ \\
\hline \multirow{4}{*}{$\mathrm{NH}_{4} \mathrm{Cl}$} & $K_{S}$ & 0.078 & 0.125 & 0.148 & 0.180 & 0.200 & 0.131 & 0.157 & 0.193 & 0.167 & 0.188 \\
\hline & SE & 0.008 & 0.007 & 0.005 & 0.008 & 0.023 & 0.008 & 0.008 & 0.004 & 0.006 & 0.015 \\
\hline & $\mathrm{R}^{2}$ & 0.929 & 0.965 & 0.988 & 0.982 & 0.890 & 0.975 & 0.981 & 0.997 & 0.985 & 0.938 \\
\hline & $\mathrm{SE} / K_{S}$ & $10 \%$ & $6 \%$ & $3 \%$ & $4 \%$ & $12 \%$ & $6 \%$ & $5 \%$ & $2 \%$ & $4 \%$ & $8 \%$ \\
\hline \multirow{4}{*}{$\mathrm{Na}_{2} \mathrm{SO}_{4}$} & $K_{S}$ & 0.567 & 0.887 & 0.987 & 1.197 & 1.378 & 0.710 & 0.812 & 0.983 & 1.075 & 1.379 \\
\hline & $\mathrm{SE}$ & 0.040 & 0.050 & 0.066 & 0.084 & 0.157 & 0.038 & 0.027 & 0.032 & 0.075 & 0.123 \\
\hline & $\mathrm{R}^{2}$ & 0.953 & 0.969 & 0.957 & 0.953 & 0.917 & 0.981 & 0.992 & 0.993 & 0.958 & 0.940 \\
\hline & $\mathrm{SE} / K_{S}$ & $7 \%$ & $6 \%$ & $7 \%$ & $7 \%$ & $11 \%$ & $5 \%$ & $3 \%$ & $3 \%$ & $7 \%$ & $9 \%$ \\
\hline \multirow{4}{*}{$\left(\mathrm{NH}_{4}\right)_{2} \mathrm{SO}_{4}{ }^{\mathrm{a}}$} & $K_{S}$ & 0.464 & 0.492 & 0.540 & 0.642 & N.A. & 0.481 & 0.506 & 0.556 & 0.598 & 0.612 \\
\hline & SE & 0.015 & 0.020 & 0.032 & 0.046 & N.A. & 0.012 & 0.016 & 0.016 & 0.021 & 0.022 \\
\hline & $\mathrm{R}^{2}$ & 0.994 & 0.990 & 0.979 & 0.970 & N.A. & 0.994 & 0.990 & 0.992 & 0.988 & 0.987 \\
\hline & $\mathrm{SE} / K_{S}$ & $3 \%$ & $4 \%$ & $6 \%$ & $7 \%$ & N.A. & $2 \%$ & $3 \%$ & $3 \%$ & $4 \%$ & $4 \%$ \\
\hline \multirow{4}{*}{$\mathrm{NaCl}^{\mathrm{b}}$} & $K_{S}$ & N.A. & 0.235 & 0.281 & 0.296 & 0.299 & 0.198 & 0.228 & 0.267 & 0.306 & 0.321 \\
\hline & $\mathrm{SE}$ & N.A. & 0.018 & 0.015 & 0.017 & 0.013 & 0.004 & 0.003 & 0.003 & 0.003 & 0.009 \\
\hline & $\mathrm{R}^{2}$ & N.A. & 0.949 & 0.976 & 0.970 & 0.984 & 0.997 & 0.999 & 0.999 & 0.999 & 0.994 \\
\hline & $\mathrm{SE} / K_{S}$ & N.A. & $8 \%$ & $5 \%$ & $6 \%$ & $4 \%$ & $2 \%$ & $1 \%$ & $1 \%$ & $1 \%$ & $3 \%$ \\
\hline
\end{tabular}

${ }^{\mathrm{a}}$ ref. $^{1 \mathrm{~b}}$ ref. $^{2}$ 

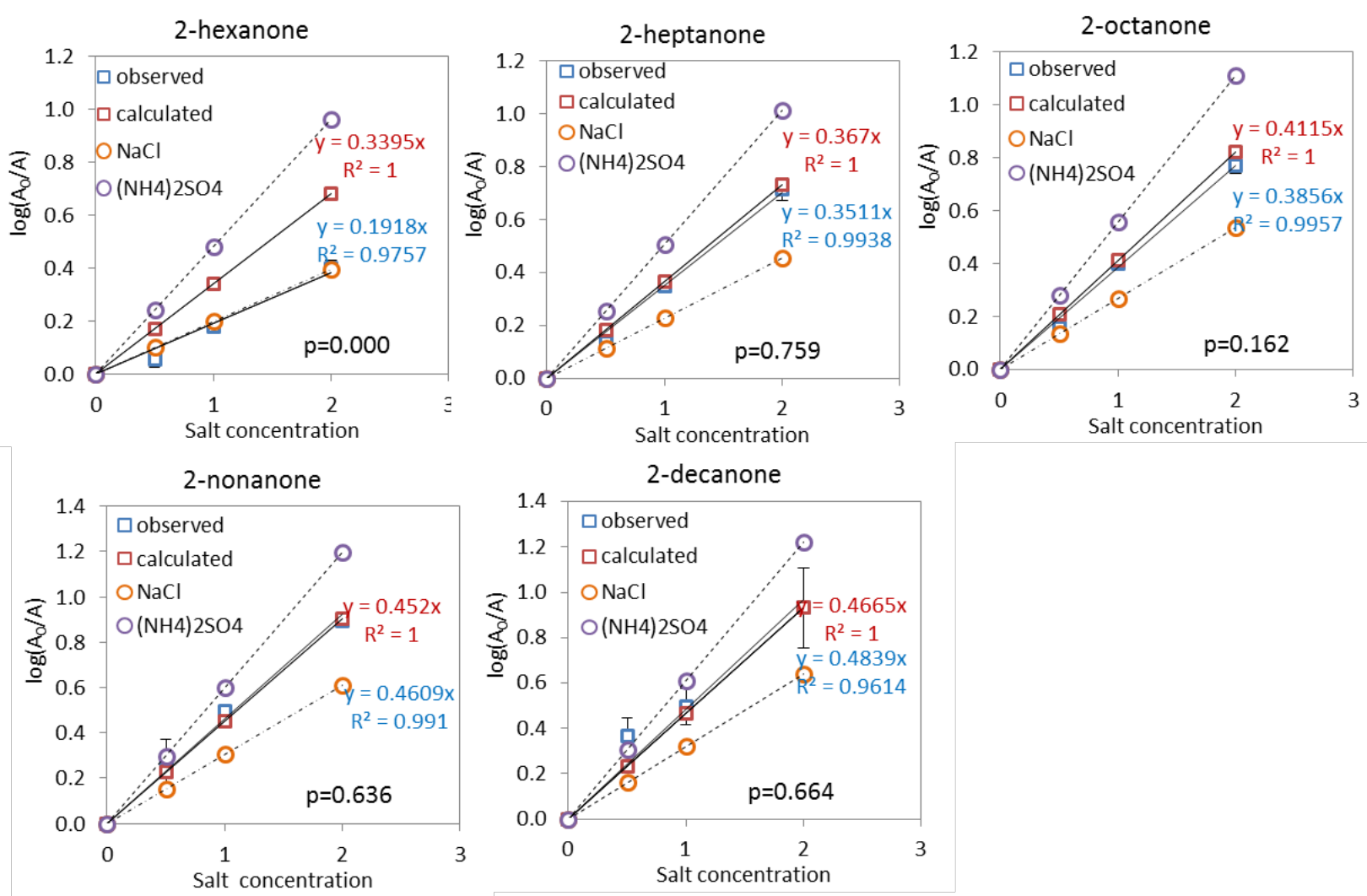

Figure 5 Salting out effect in salt mixture (1: 1 mole ratio $\mathrm{NaCl}$ and $\left.\left(\mathrm{NH}_{4}\right)_{2} \mathrm{SO}_{4}\right)$ measured using the SHPD method. The $\mathrm{Y}$ axis $\log \left(K_{1 / \text { salt water }} / K_{1 / \text { water }}\right)$ in the SHPD method corresponds to the logarithm of the ratio between GC peak areas in pure water and salt solutions $\left(\log \left(\mathrm{A}_{0} / \mathrm{A}\right)\right)$. Because in the SHPD method, the aqueous phase concentration were measured. Blue and red squares (with equation and $\mathrm{R}^{2}$ ) show observed salting out effect in the salt mixtures and calculated salting out effect by assuming additivity. Error bars for the observed values were calculated from 4 replicates at each concentration. Error bars for the calculated $K_{S, m i x}$ values were calculated from standard errors of $K_{S}$ for individual salt according to equation (2). In order to compare salting out effect of the mixtures to $\mathrm{NaCl}$ and $\left(\mathrm{NH}_{4}\right)_{2} \mathrm{SO}_{4}$, the salting out effect in $\mathrm{NaCl}$ and $\left(\mathrm{NH}_{4}\right)_{2} \mathrm{SO}_{4}$ solutions was shown by the orange and purple circles, respectively. $p$-values from analysis of covariance were shown for each compound. 


\section{References}

1. Wang, C.; Lei, Y.D.; Endo, S.; Wania, F., Measuring and modeling the salting-out effect in ammonium sulfate solutions. Environ. Sci. Technol. 2014, 48, 13238-13245.

2. Endo, S.; Pfennigsdorff, A.; Goss, K.U., Salting-out effect in aqueous NaCl solutions: trends with size and polarity of solute molecules. Environ. Sci. Technol. 2012, 46, 1496-1503.

3. Endo, S.; Watanabe, N.; Ulrich, N.; Bronner, G.; Goss, K.-U., UFZ-LSER database v 2.1 [Internet], Leipzig, Germany, Helmholtz Centre for Environmental Research-UFZ, 2016. [accessed on 29.05.2016]. Available from http://www.ufz.de/index.php?en=31698\&contentonly=1\&lserd_data[mvc] $=$ Public/start.

4. Almeida, M.B.; Alvarez, A.M.; Demiguel, E.M.; Delhoyo, E.S., Setchenow coefficients for naphthols by distribution method. Canadian Journal of Chemistry-Revue Canadienne De Chimie 1983, 61, 244-248.

5. Sada, E.; Kito, S.; Ito, Y., Solubility of toluene in aqueous salt solutions. J. Chem. Eng. Data 1975, 20, 373-375.

6. Xie, W.H.; Shiu, W.Y.; Mackay, D., A review of the effect of salts on the solubility of organic compounds in seawater. Marine Environmental Research 1997, 44, 429-444.

7. Sanemasa, I.; Arakawa, S.; Araki, M.; Deguchi, T., The effects of salts on the solubilities of benzene, toluene, ethylbenzene, and propylbenzene in water. Bulletin of the Chemical Society of Japan 1984, 57, 1539-1544.

8. Andersson, M.P.; Stipp, S.L.S. Predicting hydration energies for multivalent ions. Journal of Computational Chemistry 2014, 35, 2070-2075.

9. Görgényi, M.; Dewulf, J.; Van Langenhove, H.; Heberger, K., Aqueous salting-out effect of inorganic cations and anions on non-electrolytes. Chemosphere 2006, 65, 802-810. 